Who would mourn democracy? Liberals might, but it depends on who's in charge

Rachele Benjamin ${ }^{1}$, Kristin Laurin ${ }^{1}$, and Mindy Chiang ${ }^{2}$

${ }^{1}$ University of British Columbia, Department of Psychology

${ }^{2}$ University of British Columbia, Educational and Counselling Psychology

Corresponding author: Rachele Benjamin

Department of Psychology

2136 West Mall

Vancouver, BC, Canada, V6T $1 Z 4$

rachele.benjamin@psych.ubc.ca 


\begin{abstract}
Despite widespread support for the principles of democracy, democratic norms have been eroding globally for over a decade. We ask whether and how political ideology factors into people's reactions to democratic decline. We offer hypotheses derived from two theoretical lenses, one considering ideologically-relevant dispositions, and another considering ideologically-relevant situations. Pre-registered laboratory experiments combined with analyses of World Values Survey data indicate that there is a dispositional trend: Overall, liberals are more distressed than conservatives by low democracy. At the same time, situational factors also matter: This pattern emerges most strongly when the ruling party is conservative, and disappears (though it does not flip into its mirror image) when the ruling party is liberal. Our results contribute to ongoing debates over ideological symmetry and asymmetry; they also suggest that, if democracy is worth protecting, not everyone, everywhere will feel the urgency.
\end{abstract}

Keywords: democracy; political psychology; happiness; Moral Foundations Theory; System Justification Theory 
DEMOCRACY AND IDEOLOGY

\section{Who would mourn democracy? Liberals might, but it depends on who's in charge}

Democracy worldwide is stronger than it was a half-century ago (Huntington, 1993; Inglehart, 1997; Welzel, 2013). Stronger, that is, for now: Democratic norms have been eroding globally for over a decade (Bermeo, 2016; Diamond, 2015b; Plattner, 2015), and more and more citizens and politicians are willing to advance their own interests at the expense of upholding democracy (Graham \& Svolik, 2020; McCoy, Simonovits, \& Littvay, 2020; see also Waldron, 2020).

A large majority of people in the world value democratic systems of government (Pew Research Center, 2017a) and most celebrate the more substantive principles of democracy: individual liberties, freedoms, and the rule of law, as well as voting (Pew Research Center, 2019a, 2020; see also Berlin, 1969; Diamond, 2015a; Macpherson, 2016). This large majority likely finds democratic backslide in their countries upsetting to some degree. But in addition to the minority who directly oppose democratic systems of government (Adorno et al., 1950; Altemeyer, 1981), there are those who may support them in principle, but who prioritize other societal outcomes more strongly. Those for whom democracy is less of a priority may correspondingly feel less upset by its demise.

In this paper, we explore ideological differences in who finds weakened democracy upsetting. We use two theoretical lenses to predict such differences. One focuses on ideologically relevant dispositional factors, which are likely to endure across time and place; the other on ideologically relevant situational factors, which can vary with the political context.

\section{Ideologically relevant dispositions and feelings about democracy}

Our first lens asks about ideologically linked dispositions that might shape reactions to weaker democracy. This lens presumes that ideological differences will be stable across time and 


\section{DEMOCRACY AND IDEOLOGY}

place. There are at least two dispositions that reliably vary between liberals and conservatives and that could plausibly relate to people's feelings about democracy; together they make the theoretical case that conservatives will feel less upset by weaker democracy, across most times and places one might look.

\section{The value of equality}

First, liberals are disposed to value equality more than are conservatives (Graham et al., 2009, 2011; Haidt \& Graham, 2007). Equality is central to the very notion of democracy (e.g., Dahl, 1998; see also Duggan, 2012; Mallock, 2017), which is defined by the provision of equal rights, opportunities, and influence in political decision-making (Singer, 1973). Together, these associations suggest democracy may be especially strongly aligned with liberals' beliefs and values, and that liberals might thus place a higher relative value on democracy. Indirectly supporting this idea, one study found that liberals, more than conservatives, opposed policies that were undemocratic, even when the policies were matched to each participant's ideology such that they offered a partisan advantage (McCoy et al., 2020). In this study, participants imagined that their preferred party was in power, and was considering undermining democracy by, for example, banning protests and disregarding unfavorable court rulings that threatened their preferences. Democrats opposed these undemocratic measures more than did Republicans, even though from all participants' perspective, the measures aimed to help advance their group's agenda. These findings align with the idea that liberals place democracy in higher priority, relative to their other goals. If so, we would expect liberals to be more distressed than conservatives when their country fails to live up to democratic values.

\section{System justification}




\section{DEMOCRACY AND IDEOLOGY}

Second, conservatives are better equipped to defend against negative information about their nation (Jost, Pelham, Sheldon, \& Sullivan, 2003). That is, they are generally more effective system justifiers (Jost, 2019; Jost, Banaji, \& Nosek, 2004), and may thus be more able to rationalize away signs they are living in a weaker democracy. In almost all countries (though see Langer et al., 2020 for France's exceptional status in this regard), conservatives tend to justify the system more than liberals, protecting themselves from the psychological distress of seeing their nations as flawed (Napier \& Jost, 2008).

System justification can take many forms. For instance, people can adjust their attitudes to favor the new status quo (Kay et al., 2009; Kay, Jimenez, \& Jost, 2002). Using this strategy, conservatives might devalue democracy to the extent they perceive its absence in their country. Alternatively, people can simply refuse to believe information that casts their nation in a negative light (Jost, et al., 2003; see also Haines \& Jost, 2000). Using this strategy, conservatives might dismiss threats to democracy as overblown or fake news. In either case, this would mean conservatives are better able than liberals to perceive the current or anticipated state of their nation as aligned with their preferences. This system justification pathway also predicts liberals would feel more distressed than conservatives by signs of low democracy.

\section{Ideologically relevant situations and feelings about democracy}

Our second lens asks how ideologically relevant situations might shape how people feel about weaker democracy. This lens assumes that people's feelings about democracy can vary according to their analysis of democracy's instrumental value for their other priorities. Through this lens, any ideological difference in feelings about democracy is contingent on the situation, because in different political contexts, democratic procedures may yield different kinds of outcomes. 


\section{DEMOCRACY AND IDEOLOGY}

It is challenging to characterize the specific social, economic and political contexts that would factor into how a citizen evaluates democracy's likely effects on their broader priorities. Moreover, it is neither the objective situation nor its objective effects that will factor into everyday citizens' calculations, but rather their subjective, and at times inaccurate and idiosyncratic, perceptions. That said, one important political context is how well citizens feel the current government represents them (see Morisi, Jost, \& Singh, 2019). If democracy is weaker, citizens likely feel they have fewer mechanisms by which they can advocate for change, that the status quo is more likely to persist, and that current leaders are freer to exercise power. As a result, those whose political views clash with the current government's ideology may see a weaker democracy as especially distressing, leaving them feeling helpless in the face of policies they oppose. In contrast, those who share the current government's ideology may not be so bothered, with some even seeing it as an advantage, at least in the short term.

Some evidence already indirectly supports the notion that people's feelings about democracy fluctuate with their political context, and in particular with their match with the current government's ideology. The same study described above also included a condition where participants imagined that the opposing party was in power, and was considering the same undemocratic measures, to benefit their own agendas. Members of both parties were much more likely to oppose undemocratic measures in this condition, compared to when it was their preferred party that was poised to implement and stood to benefit from them (McCoy et al., 2020; see also Graham \& Svolik, 2020). In other words, both liberals and conservatives became more ardent defenders of democracy in some situations, specifically when they disagreed with the ideology of the party proposing to circumvent it. ${ }^{1}$

\footnotetext{
${ }^{1}$ Of course, contextual factors beyond a person's ideological match with the ruling party probably also enter into their analysis of how democracy will affect their other political priorities. For example, contemporary Americans
} 


\section{DEMOCRACY AND IDEOLOGY}

Unlike the dispositional lens, the situational lens predicts that liberals and conservatives are both capable of shrugging in the face of democratic demise. When government leaders are conservative, liberal citizens should be more upset by weaker democracy while conservative citizens remain indifferent; when leaders are instead liberal, we should observe the opposite.

\section{Connections with ongoing debates in the literature}

One driving force behind our research was the pressing need to better understand how citizens respond to the kind of democratic decline the entire world has been experiencing in recent decades. Understanding this response can lay the groundwork for future research about how to modulate it, and leverage it into action to bolster democracy, a political system that in general has benefited nations (Barro, 1996; Helliwell, 1992; Przeworski et al., 2000) as well as individuals (Diener et al., 1999; Dorn et al., 2006; Stutzer \& Frey, 2003). But in addition to this, our research builds upon and extends key theoretical positions in social psychology. For one thing, the lenses we offer here follow from decades of theorizing on the distinction and interplay between dispositions and situations, both in general (Bem \& Allen, 1974; Lewin, Lippitt, \& White, 1939; McAdams, 1995; Mischel, 2013/1968; Reis, 2008; Ross \& Nisbett, 1991), and as they guide political attitudes and emotions (see Gerber et al., 2010; Pliskin, Ruhrman, \& Halperin, 2020). For another, our specific predictions have relevance to ongoing debates about whether various ideological phenomena are asymmetrical versus symmetrical — that is, more pronounced at one end of the political spectrum versus equally prevalent at both ends.

Symmetry versus asymmetry in political psychology. Proponents of asymmetry argue for example that conservatives are more prejudiced against their opponents (e.g., Ganzach \&

commonly believe that more democracy in the form of greater political participation produces better electoral results for Democrats (Gomez, Hansford, \& Krause, 2007; Fraga, 2018; Hansford \& Gomez, 2010; though some scholars dispute whether this is true, Citrin, Schickler, \& Sides, 2003). We focus here on the ideology of the current government as it is likely a relevant factor comparable across many different political cultures. 


\section{DEMOCRACY AND IDEOLOGY}

Schul, 2020; Jost et al., 2017; Sibley \& Duckitt, 2008; Stern \& Axt, 2021), show greater motivated bias in their reasoning (Jost et al., 2003) and have more rigid thinking styles (Carney et al., 2008; Jost, 2017). Conversely, proponents of symmetry argue that both conservative and liberals are similarly willing to discriminate against one another (e.g., Brandt et al., 2014; Chambers et al., 2013; Crawford \& Pilanski, 2014; Moore-Berg et al., 2020; Toner, Leary, \& Asher, 2013), show similar levels of emotional and cognitive bias against one another (Ditto et al., 2019; Steiger et al., 2019), and use similarly simple thinking in approaching partisan issues (Conway et al., 2016).

Relating these debates to our theorizing, the dispositional lens we offer predicts a stable ideological asymmetry, such that conservatives will always and everywhere be less distressed than liberals about weak democracy. The situational lens we offer also predicts asymmetries in terms of what we can directly observe - that conservatives and liberals in many contexts will feel differently about democracy_but it predicts that these observable asymmetries arise from a symmetrical process: It posits that both sides respond in the same manner to feeling well- versus poorly represented by current governments. Drawing upon the traditional conceptualization of symmetry in the literature (Ditto et al., 2019; Skitka \& Bauman, 2008; though see Baron \& Jost, 2019), the situational lens predicts that both ideological groups show an equal tendency to be more upset by democratic declines that take place while their views are not represented in government, and less upset by these same declines when their views match those of current government.

The case of authoritarianism. Beyond the question of (a)symmetry in general, our work is particularly relevant to ongoing debates over authoritarianism. Authoritarianism is typically conceptualized as a personality trait, with its key features being preferences for absolutist forms 


\section{DEMOCRACY AND IDEOLOGY}

of government (Adorno et al., 1950), dominant leaders (Altemeyer, 1998), and submissive citizens (Adorno, 1950; Altemeyer, 1996). These features inversely track many components of democracy, such that a strong authoritarian is likely to oppose democracy, and to feel little distress if not outright delight at its demise (Altemeyer, 1988). At the same time, a nonauthoritarian might care deeply about democracy, or they might not: There are other personality traits that independently predict support for democracy (e.g., interpersonal trust, see Sullivan \& Transue, 1999), and a non-authoritarian might devalue democracy if they hold other political goals in higher priority. Still, to the extent that authoritarians are unlikely to feel distressed by the demise of democracy, our findings may be relevant to ongoing debates about authoritarianism.

Scholars disagree about whether the authoritarian personality trait is asymmetrically more prevalent among conservatives (e.g., Altemeyer, 1998; Nilsson \& Jost, 2020), or symmetrically prevalent at both ends of the political spectrum (e.g., Conway et al., 2018; Costello et al., 2020). Our dispositional lens is particularly in line with the asymmetrical view of authoritarianism: If conservatives tend toward authoritarianism, it makes sense that they would also value equality less (for an authoritarian, leaders and followers coexist in an unequal hierarchy), justify the system more (for an authoritarian, the leaders who run the system know what is best), and feel less distressed by a weaker democracy (which, for an authoritarian, is not the correct tool for political decision making).

In contrast, our situational lens predicts that it is not conservatives specifically, but rather anyone who feels the current leaders are on their side, who should devalue democracy, and feel comfortable with it being weak. It may seem strange to connect a situational perspective to the authoritarian personality. But even if authoritarianism is a stable personality trait, the symmetrical view of authoritarianism implies that it is one that guides behavior in context- 


\section{DEMOCRACY AND IDEOLOGY}

specific ways, contingent on the leader / follower hierarchy. For example, proponents of authoritarian symmetry point out that, just as there are authoritarian rightists who unconditionally support only leaders they perceive as conservative (e.g., military and religious leaders), there are authoritarian leftists who unconditionally support only leaders they perceive as liberal (e.g., scientific experts and leaders of progressive movements; Conway et al., 2018). This pattern is very much in line with the predictions of our situational lens.

The studies we report here thus speak to debates over ideological symmetry versus asymmetry in general. They may also indirectly contribute to the question of whether antidemocratic authoritarianism is a dispositional trait typical of one side of the political spectrum, or rather has a similar presence on both sides, guiding action differently depending on the circumstances.

\section{Overview and current studies}

Seven studies combine experimental and archival methods to examine ideological differences in how people react to signs that their country's democracy is weak. We evaluate our data through two contrasting lenses, one focused on dispositional and enduring differences between conservatives and liberals, and one focused on situations, with individuals across the spectrum being particularly concerned with democracy when the political context dictates they need it to change the status quo and advance their agenda. By considering in tandem these two possibilities, and assessing which most closely matches our empirical observations, we answer calls for political psychologists to consider not only individual actors, but the broader political context in which they exist (e.g., Frimer, Skitka, \& Motyl, 2017; Jost, Halperin, \& Laurin, 2020; Proch, Elad-Strenger, \& Kessler, 2019). We also help address ongoing debates in the field over 


\section{DEMOCRACY AND IDEOLOGY}

ideological symmetry (Brandt et al., 2014; Ditto et al., 2019; Jost et al., 2017; Pliskin et al., 2020).

Study 1 evaluates ideological differences in reactions to weak democracy in the particular context of recent years in America, where both our lenses would predict liberals would be more upset than conservatives. Study 2 replicates the initial findings while beginning to test unique predictions of the dispositional lens, measuring the value of equality and system justification as mediators. Studies 3a through 4 tested a unique prediction of the situational lens by comparing a different conservative-led country (the UK) to a liberal-led one (Canada), as well as conservative-led to liberal-led US states. Finally, Study 5 analyzed World Values Survey data to examine both lenses together: Does the ideological asymmetry emerge in an overall analysis covering all available countries, or does the asymmetry flip depending on the ideology of the current governing party?

When we began conducting these studies, we aimed to answer a somewhat different question than the one we pose here: We asked how perceptions of democracy causally influenced liberal versus conservative well-being. For that reason, our studies included affective measures of distress and happiness that remain relevant to our current purposes, as well as cognitive measures of security appraisals and life satisfaction that lost their pertinence as our research question evolved. Part of what drove this evolution in our thinking is that, while the affective measures reliably produced the same pattern, the cognitive measures showed inconsistent results. We summarize the results for the cognitive measures briefly in the main text, after reporting all the experimental studies, and describe them fully in the online supplement.

\section{Study 1}




\section{DEMOCRACY AND IDEOLOGY}

We launched Study 1 on Amazon Mturk in November 2017, during the Trump presidency and shortly after the Economist Intelligence Unit (EIU) downgraded America from full to flawed democracy in (EIU, 2016), a democratic backslide from which it would not soon recover (EIU, 2020). Scholars, experts, and pundits have laid the blame for this at the feet of political elites on the right (Brock, 2005; Drutman, 2021; Levitsky \& Ziblatt, 2016; Lührmann, Medzihorsky, \& Lindberg, 2021; Mettler \& Lieberman, 2020); if this is true, it may be that citizens who voted for those elites feel comfortable with the resulting loss of democracy. Indeed, both our lenses predict that American conservatives in our sample would be less upset by information about their country's democratic weakness, either because they are dispositionally less concerned with democracy, or because the Republican government of the day made liberals especially concerned with preserving their ability to democratically object to that government. Thus Study 1 cannot permit us to distinguish between our two lenses, rather it tested a falsifiable prediction that is common to both.

Participants played one of three versions of a quiz game. In the low and high democracy conditions, the game asked them to rank a set of countries including their own from most to least democratic. To manipulate perceived democracy while avoiding deception, we varied which countries participants ranked. We then gave them feedback showing the countries' true Democracy Index rankings, and emphasizing the reasons accounting for their country's relative position. In the low democracy condition, we presented the US alongside mostly more democratic countries and our feedback message emphasized its democratic weaknesses; in the high democracy condition, we presented it among mostly less democratic countries and emphasized its democratic strengths. Participants in both conditions reported their feelings of 


\section{DEMOCRACY AND IDEOLOGY}

distress both before and after the manipulation, allowing us to sensitively test how each condition's quiz made them feel.

In a third condition, the control condition, participants played a similar quiz game about countries' desirability as vacation spots. This information had little do with democracy, and enabled us to account for any baseline tendency for participants' distress levels to change over time when playing a quiz game.

We pre-registered materials and analyses

\section{(https://osf.io/kd4mq/?view_only=3fc1517350a9478aad7a074bdf6f8611).}

\section{Methods}

Participants. We obtained a sample of 407 participants from American Mturk (age $M=$ 35.71, $S D=10.98,56 \%$ female, $72 \%$ European descent, political orientation $M=4.64, S D=2.64$ on a scale from 1 [extremely liberal] to 10 [extremely conservative]). We made no exclusions, as we accidentally omitted the attention check from our survey (see uploaded survey documents at OSF link), but included these checks in subsequent studies. In this and all subsequent Mturk studies, we used Cloud Research to recruit participants (Litman, Robinson, \& Abberbock, 2017); this allowed us to set the following restrictions for all our studies: Participants had to have completed a maximum of 5,000 HITS with a HIT approval rating of 80-100\%, and could only participate if they had not participated in previous studies in this line of work.

Procedure. Participants first completed a baseline measure of distress, using sliding scales (ranging from 0 to 100) to indicate their current experience of each of several emotions: angry, depressed, fearful, worried and happy (reverse scored). We averaged them to form an index of baseline distress $(M=16.95, S D=16.99 ; \alpha=0.83)$. 


\section{DEMOCRACY AND IDEOLOGY}

Next, in the low and high democracy conditions, participants read a passage about the EIU and its Democracy Index. They read about the EIU's criteria for this index: (1) Electoral process and pluralism, (2) Civil liberties, (3) The functioning of government, (4) Political participation, and (5) Political culture. In the control condition they instead read a (fictional) passage about Conde Nast's rankings of how desirable countries are as vacation spots, based on objective indicators (e.g., number of festivals, affordability, food and culture).

In both these conditions, participants then ranked nine countries, including their own, the United States. In the low democracy condition, the other countries included one rated as less democratic by the EIU (the Czech Republic) and seven rated as more democratic (Norway, Iceland, Sweden, Switzerland, Denmark, New Zealand, the Czech Republic, and Finland). After providing their rankings, participants saw the countries' true ratings alongside a message emphasizing the flaws in their country's democracy, drawn from the EIU's analysis (see Table 1). In the high democracy condition, the other countries instead included seven rated as less democratic (North Korea, China, Central African Republic, Syria, Saudi Arabia, Russia, and Afghanistan) and one rated as more democratic by the EIU (Australia); participants in this condition also saw the true rankings alongside a message that instead emphasized the healthy aspects of their country's democracy (see Table 1).

In the control condition, participants saw similarly formatted information about a fictional Conde Nast metric of vacation desirability. They played a similar game, where they ranked their country along with a list of moderately desirable vacation spots and learned that their country ranked in the middle (see Table 1).

Table 1. Messages presented alongside expert rankings from the Democracy Index (low and high democracy conditions) or Conde Nast (control condition)

Low Democracy High Democracy

Control 


\section{DEMOCRACY AND IDEOLOGY}

Your country, America, was downgraded in 2016 to a flawed democracy. This was because America has free elections but is weighed down by weak governance, an underdeveloped political culture, and low levels of political participation.
The U.S. is a full democracy, meaning that civil liberties and basic political freedoms are not only respected, but also reinforced by a political culture conducive to the thriving of democratic principle. There is a valid, functioning system of governmental checks and balances.
The U.S. is full of attractions and museums that are both enjoyable and well-maintained. It is a world leader in terms of resorts and hotels, and the amount of events and festivals each year makes it a desirable vacation spot.

To ensure that any performance-related changes in mood would be the same across conditions, we told all participants that they had performed better than $87 \%$ of all others who took the quiz. Participants then completed the same five items assessing distress, which we combined into a post-manipulation index $(M=16.60, S D=17.09 ; \alpha=0.83)$.

At the end of the survey, participants reported their overall political orientation using a sliding scale ranging from 1 (left/liberal) to 10 (right/conservative), in the context of a broader demographic form. A 10-point self-placement scale is commonly used in large cross-national surveys (Zuell \& Scholz, 2019) and Likert-type scales measuring relative left (or liberal) and right (or conservative) placement are by far the most frequent way researchers assess political orientation (see, e.g., Carney et al., 2008; Feldman \& Johnston, 2014; Graham et al., 2009; Jost et al., 2004). Moreover, the single-item self-placement measure is the most ubiquitous measure of political orientation, and tracks participants' general political positions better than multi-item measurements (Kroh, 2007; Lesschaeve, 2017).

As noted above, in this and all subsequent studies we also assessed cognitive well-being (specifically, global life satisfaction and momentary appraisals of security). As also noted above, results on these measures were inconsistent and not directly relevant to the question of who feels 


\section{DEMOCRACY AND IDEOLOGY}

upset by weaknesses in their country's democracy; we report them in full in the SOM and summarize them briefly across studies later in the paper. ${ }^{2}$

\section{Results}

Both our theoretical lenses predicted that, in this study, American liberals would feel more distressed by information suggesting their country was undemocratic, compared to American conservatives. We ran a multilevel regression model predicting participants' feelings of distress from whether distress was measured at baseline (0) or post-manipulation (1), condition (dummy coded with the low democracy condition as the reference group), political orientation (centered), all interaction terms, and random intercepts for participants (see Table 2;

Figure 1 and most other figures in this paper use difference scores between baseline and postmanipulation measures to illustrate the interactions, with error bars representing standard errors).

Significant condition $\times$ timing interactions indicated that on average, people were more distressed by information suggesting their country was not very democratic than by information in the other two conditions (as pre-registered we also tested this effect using condition $\times$ timing mixed model ANOVAs and found the same results; see SOM). More critically, significant threeway interactions indicated this tendency was moderated by political orientation, and stronger among liberals than conservatives: The condition $\times$ timing interactions were strong among liberals $\left(-1 \mathrm{SD}\right.$ on the scale; blow vs. control $=-9.69, t=-6.58, p<.001, C I_{95}=[-12.57,-6.82]$, blow vs. high $\left.=-7.39, t=-4.97, p<.001, C_{95}=[-10.30,-4.49]\right)$, but weaker (though still present) among

\footnotetext{
${ }^{2}$ Study 1, but no subsequent study, also administered the Positive and Negative Affect Schedule (PANAS; Watson, Clark, \& Tellegen, 1988); this measure, notoriously unstable and sensitive to only high-arousal emotion states (Diener et al, 2010; Egloff et al., 2003; Harmon-Jones \& Harmon-Jones, 2016) did not support our hypotheses (see SOM for details). Study 1 also included participants' political orientation separately regarding social issues (e.g., abortion) and economic issues (e.g., taxation). We pre-registered no analyses for these measures, but they showed similar patterns as the ones we report here, significantly for social but not for economic orientation.
} 
conservatives $\left(+1 \mathrm{SD}\right.$ on the scale; blow vs. control $=-5.47, t=-3.77, p<.001, C I_{95}=[-8.30,-2.64]$,

blow vs. high $\left.=-3.15, t=-2.20, p=.028, C I_{95}=[-5.93,-0.36]\right)$.

Table 2. Study 1 full model fixed effects and simple effects within condition (total $\mathrm{N}=$ 407 [814 observations])

\begin{tabular}{lcccc}
\hline & $b$ & $t$ & $p$ & $.95 C I$ \\
\hline Coefficient & \multicolumn{4}{c}{ Full Model Fixed Effects } \\
\hline (Intercept) & 16.13 & 10.85 & $<.001$ & {$[13.23,19.03]$} \\
Control Dummy Code & 1.70 & 0.82 & .415 & {$[-2.36,5.76]$} \\
High Dummy Code & 0.38 & 0.18 & .857 & {$[-3.67,4.42]$} \\
Political orientation & 0.86 & 1.53 & .126 & {$[-0.23,1.95]$} \\
Baseline vs. post & 4.06 & 5.49 & $<.001$ & {$[2.62,5.50]$} \\
Control Dummy Code $\times$ Baseline vs. post & -7.58 & -7.32 & $<.001$ & {$[-9.60,-5.56]$} \\
High Dummy Code $\times$ Baseline vs. post & -5.27 & -5.11 & $<.001$ & {$[-7.28,-3.26]$} \\
Political orientation $\times$ Baseline vs. post & -0.68 & -2.42 & .016 & {$[-1.22,-0.13]$} \\
Control Dummy Code $\times$ Political orientation & -1.50 & -1.91 & .057 & {$[-3.04,0.03]$} \\
High Dummy Code $\times$ Political orientation & -0.97 & -1.23 & .218 & {$[-2.51,0.56]$} \\
Control Dummy Code $\times$ Baseline vs. post $\times$ Political orientation & 0.80 & 2.05 & .041 & {$[0.04,1.57]$} \\
High Dummy Code $\times$ Baseline vs. post $\times$ Political orientation & 0.81 & 2.06 & .040 & {$[0.04,1.57]$} \\
\hline Among & Simple slopes (change in distress) \\
\hline$\quad$ Low democracy condition & & & & \\
$\quad$ Liberals $(-1$ SD) & 5.66 & 4.45 & $<.001$ & {$[3.17,8.15]$} \\
$\quad$ Conservatives $(+1$ SD) & 2.09 & 1.64 & .103 & {$[-0.40,4.58]$} \\
$\quad$ Control condition & & & & \\
$\quad$ Liberals $(-1$ SD) & -3.88 & -3.63 & $<.001$ & {$[-5.98,-1.79]$} \\
$\quad$ Conservatives $(+1$ SD) & -3.22 & -3.00 & .003 & {$[-5.31,-1.12]$} \\
$\quad$ High democracy condition & & & & \\
$\quad$ Liberals $(-1$ SD) & -1.56 & -2.33 & .022 & {$[-2.88,-0.25]$} \\
$\quad$ Conservatives (+1 SD) & -0.88 & -1.31 & .194 & {$[-2.19,0.44]$} \\
\hline
\end{tabular}

Figure 1. Estimated change in distress by liberal (-1 SD) and conservative (+1 SD) participants.

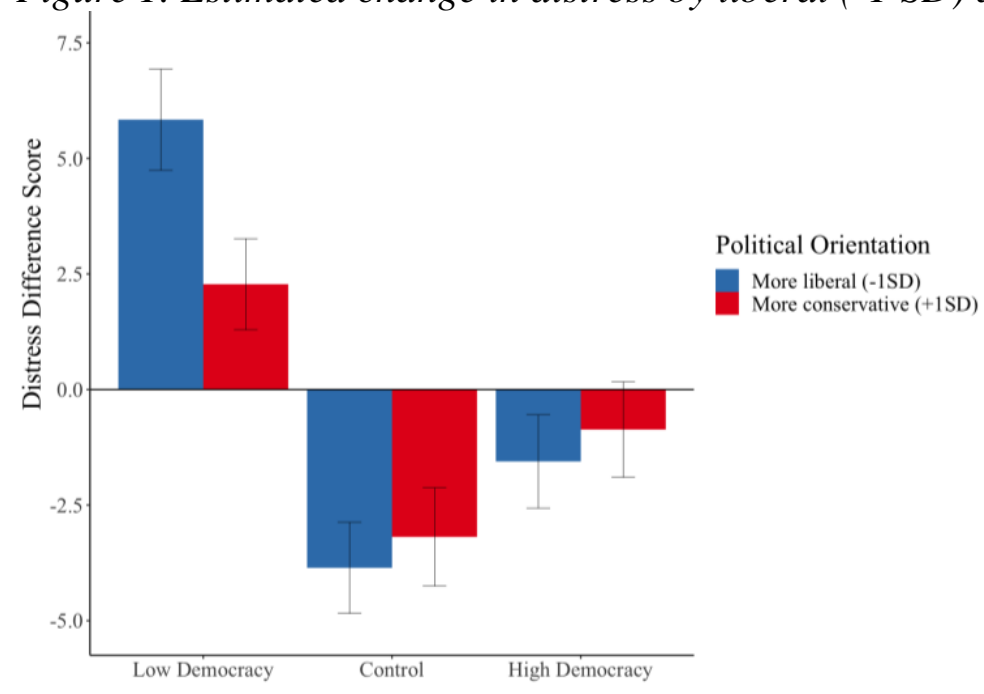

Table 2 also presents the simple slopes reflecting change in distress separately among

liberals (one standard deviation below the mean) and conservatives (one standard deviation 


\section{DEMOCRACY AND IDEOLOGY}

above the mean) and within each experimental condition. Across these analyses, the only group whose distress increased significantly was liberals in the low democracy condition, by 0.33 standard deviations. For conservatives in that same condition distress increased by only 0.12 standard deviations.

The bottom two rows of Table 2 suggest that learning about their country's democratic strength decreased distress among liberals but not conservatives. This pattern of simple effects is consistent with the dispositional lens as well, but the effects were much smaller; moreover, running the model using the high democracy condition as the reference group cautions us to not overinterpret this single-study finding: The political orientation $\times$ interaction in that condition was not close to significant $(b=0.13, t=0.72, p=.472, .95 \mathrm{CI}[-0.22,0.49])$, and more importantly a very non-significant three-way interaction $(b=-0.004, t=-0.01, p=.992, .95 \mathrm{CI}[-$ $0.76,0.75])$ indicated that this pattern was nearly identical to that in the control condition.

\section{Discussion}

Study 1 provides initial evidence that, at least in contemporary America, liberals found it more distressing than conservatives to encounter information suggesting that their country is undemocratic. A pre-registered supplemental study that exactly replicated the low democracy condition from Study 1 in the same population found further confirmatory evidence (see SOM for details). These results are particularly notable in the context of an established trend for conservatives to be more sensitive to and avoidant of negative information compared to liberals (Carraro, Castelli, \& Macchiella, 2011; Hibbing, Smith, \& Alford, 2014; Oxley et al., 2008; Shook \& Fazio, 2009). The fact that conservatives were less sensitive than liberals to negative information about the state of democracy speaks to the strength of this ideological asymmetryat least in 2017 in America. 
DEMOCRACY AND IDEOLOGY

Interestingly, Study 1 revealed no parallel discrepancy in reactions to information suggesting American democracy was strong: Liberals' distress decreased directionally more than conservatives' following this information, but this pattern was nearly identical to that in the control condition, where participants learned nothing about democracy. The fact that participants' distress was not particularly responsive to the high democracy condition may reflect the fact that Americans' baseline assumption, at least at the time of the study, was that democracy in their country was in reasonable shape (Pew Research Center, 2018a), in which case simply confirming that for them would not have caused much effect. In any case, our primary concern is with reactions to low democracy, and our remaining studies focus on that condition.

Both of our theoretical lenses can account for the asymmetry documented in Study 1. It could be that ideologically-linked dispositions made liberals more distressed about democracy's decline, but it could also be that the asymmetry was driven by the situation: Democratic declines risked preventing liberals from replacing a government they never approved of (Dimlock \& Gramlic, 2020; Washington Post, 2021). In Study 2, we tested predictions unique to the dispositional lens.

\section{Study 2}

We launched Study 2 in March 2018. Its first goal was to further replicate the ideological asymmetry we observed in the low democracy condition from Study 1 (and in the supplemental study); we predicted that American liberals under a conservative government would again be more sensitive than their conservative counterparts to learning their country was not very 


\section{DEMOCRACY AND IDEOLOGY}

democratic. With this goal in mind, we more than doubled the sample size for the single condition we replicated and improved on our within-participant measurement of distress.

Study 2's second goal was to ensure our participant-facing materials did not describe democracy with an unintended liberal slant. On the one hand, the criteria we described as forming the basis of the Democracy Index in Study 1 (e.g., political process and pluralism, civil liberties, the functioning of government) are non-controversial and endorsed as important components of democracy by right-leaning groups like Freedom House (Freedom House, 2019). On the other hand, careful scrutiny identified a couple of ways in which Study 1's language might have portrayed democracy in terms especially appealing to liberals.

Study 2's third goal was to begin to examine the ideologically-linked dispositions we proposed might explain the asymmetry in responses to low democracy. We tested whether (1) liberals' relative preference for equality, and (2) conservatives' relative tendency to justify the system—-mediated the ideological asymmetry in responses to low democracy. We pre-registered methods and analyses (https://osf.io/tqpg5/?view_only=3a7b04a0e42842dcaf63617fab9d9d1d).

\section{Methods}

Participants. We pre-registered a sample size of 300 and obtained 309 valid responses from American Mturk workers. As planned, we excluded 30 participants who failed an attention check (participants read a paragraph and entered a specific word into a textbox); unexpectedly, one additional participant did not report their political orientation. This left us with a final sample of 279 (age $M=36.67, S D=11.62,55.9 \%$ female, $71 \%$ European descent, political orientation $M$ $=4.54, S D=2.53)$.

Procedure. We closely replicated the procedure from Study 1's low democracy condition, with the only differences being as follows. 


\section{DEMOCRACY AND IDEOLOGY}

Ensuring our materials did not skew liberal. This entailed two small modifications. First, in defining democracy, we safeguarded against a couple of potential misunderstandings. We wondered whether the term "pluralism" would be misinterpreted as a reference to diversity—an ideal that appeals particularly to liberals (Galston \& Galston, 1991) — and whether the phrase "civil liberties" might conjure thoughts of fights for civil rights (i.e., racial equality and gay rights) — causes viewed more favorably by liberals than conservatives (General Social Survey, 2015; Pew Research Center, 2019b; see also Sidanius, Pratto, \& Bobo, 1996). We therefore replaced the term "pluralism" with a phrase capturing its intended meaning: "presence of more than one political party", and the term "civil liberties" with a related but slightly different term: "individual rights and freedoms".

Second, our feedback message in Study 1 had mentioned weak governance and low levels of political participation as a problem with current US democracy. But many conservatives advocate for a smaller government, and some see high levels of political participation as advantaging US Democrats (Gomez et al., 2007; Fraga, 2018; Hansford \& Gomez, 2010; see also Pew Research Center, 2018b). We therefore removed mentions of weak governance and low political participation from our feedback message, replacing them with convoluted electoral process and problems ensuring rights and freedoms:

Your country, America, was downgraded in 2016 to a flawed democracy. This was because America has free elections but is weighed down by a convoluted electoral process, a failure to properly guarantee individual rights and freedoms to the same degree as other nations, and an underdeveloped political culture.

\section{Adding measures of enduring dispositional differences between liberals and}

conservatives. We introduced two scales measuring our proposed mechanisms - the Moral 


\section{DEMOCRACY AND IDEOLOGY}

Foundations Questionnaire (MFQ; Graham et al., 2009) and the System Justification Scale (Kay \& Jost, 2003) - these measures came between the measures of political orientation and baseline distress. We measured the full MFQ, but our pre-registered analyses focused only on the subscale measuring fairness: Many of that subscale's items tap into equality more than into fairness, and indeed that is how it was originally labeled (e.g., participants report how much it factors into their thinking about something was right and wrong "whether some people were treated differently than others").

Eliminating the need to administer the same items twice. Rather than administering all distress items at both timepoints, we added a sixth item ("upset") to the list of distress items, and programmed the survey to randomly select, for each participant, three items to present as the baseline measure $(M=19.26, S D=18.71, \alpha=0.89)$, with the remaining three appearing as the post-manipulation measure $(M=24.41, S D=21.68, \alpha=0.87)$. In this way, the two timepoints featured the same items across the whole sample, but individual participants could not anchor their post-manipulation responses on their baseline responses.

\section{Results}

Though we did not pre-register these analyses, we replicated the past research on which our dispositional theorizing was based, confirming that conservatives were less likely to value equality $(r=-.343, p<.001)$ and more likely to justify the system $(r=.421, p<.001)$, compared to liberals.

Replicating Study 1. We regressed distress on baseline (0) vs. post-manipulation (1), political orientation (centered), their interaction, and random intercepts for participants (see Table 3; Figure 2).

Table 3. Study 2 full model fixed effects and simple effects (total $\mathrm{N}=279$ [554 observations])

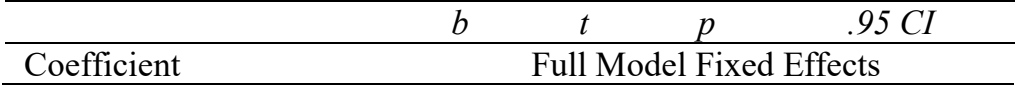


DEMOCRACY AND IDEOLOGY

\begin{tabular}{lcccc}
\hline (Intercept) & 19.29 & 16.01 & $<.001$ & {$[16.93,21.66]$} \\
Baseline vs. post & 5.03 & 4.03 & $<.001$ & {$[2.58,7.47]$} \\
Political orientation & -0.28 & -0.58 & .564 & {$[-1.21,0.66]$} \\
Interaction & -1.21 & -2.43 & .016 & {$[-2.18,-0.23]$} \\
\hline Among & \multicolumn{5}{c}{ Simple slopes (change in distress) } \\
\hline \multicolumn{1}{c}{ Liberals (-1 SD) } & 8.07 & 4.59 & $<.001$ & {$[4.63,11.52]$} \\
Conservatives (+1 SD) & 1.98 & 1.11 & .267 & {$[-1.51,5.48]$} \\
\hline
\end{tabular}

Note. There are four missing observations because three participants reported only their baseline distress and one reported only their post-manipulation distress.

Figure 2. Difference scores for liberals (-1 SD) and conservatives (+1 SD).

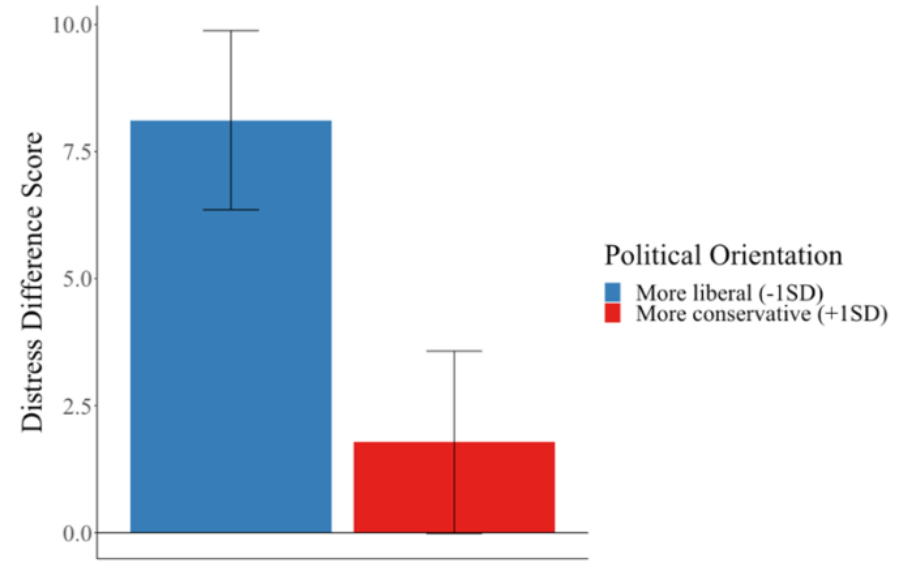

Replicating our prior findings, we found a main effect of the timing variable, suggesting that overall, participants found the low democracy quiz game distressing. More critically, and also replicating our prior findings, this was moderated by political orientation: Liberals (-1 SD political orientation) were more distressed after compared to before learning their country's democracy was in peril, by 0.43 standard deviations, but the same was not true of conservatives (+1 SD political orientation), whose distress increased non-significantly by 0.11 standard deviations.

Testing for mediation by valuing equality and / or system justification. As per our pre-registered analysis plan, we next tested whether, similar to political ideology, the value participants placed on equality and / or their tendency toward system justification also moderated their distress in response to the low democracy quiz. Both variables did (see SOM for details); the final step in our plan was then to test whether one or both of them accounted for the 


\section{DEMOCRACY AND IDEOLOGY}

ideological asymmetry. To simplify the model, we subtracted each participant's baseline score from their post-manipulation score to form an index where more positive numbers represented larger increases in distress from before to after the manipulation. We then used the lavaan package in $\mathrm{R}$ to model simultaneous mediation using political orientation as the independent variable, change in distress as the dependent variable, and valuing equality and system justification as parallel mediators (see Figure 3). (Our original pre-registered plan to use Hayes' PROCESS macro for SPSS yields nearly identical results.)

Figure 3. System justification and valuing equality fully mediate the relationship between political orientation and distress.

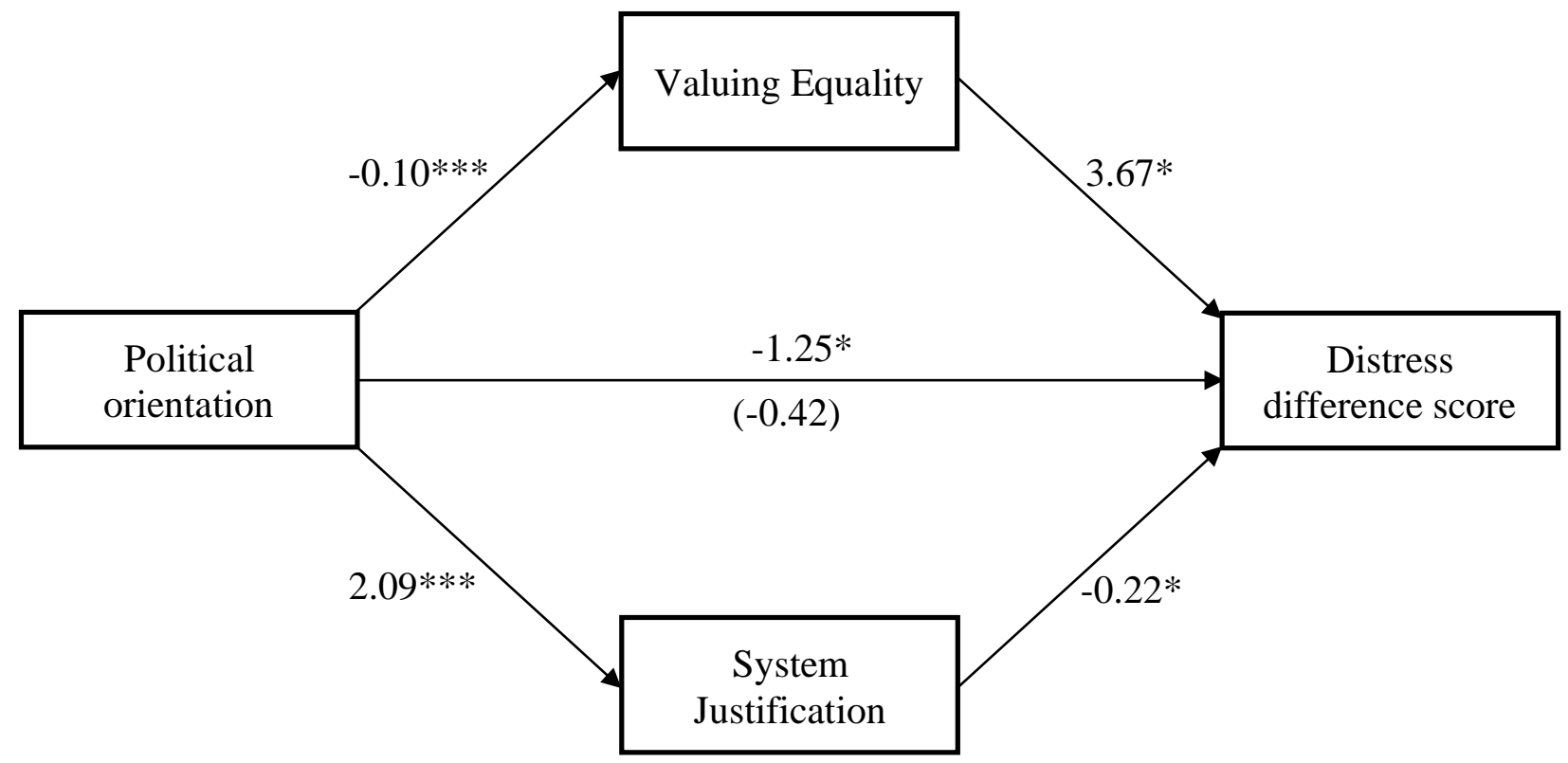

In this model, political orientation no longer predicted changes in distress, $b=-0.42, \mathrm{SE}$ $=0.57, p=.459, C I_{95}=[-1.61,0.59]$. Instead, the overall indirect effect was robust, $b=-0.83, \mathrm{SE}$ $=0.30, p=.006, C_{95}=[-1.42,-0.24]$, consistent with the idea that our mediators, which represent stable dispositional differences between liberals and conservatives (Haidt \& Graham, 2009; Jost et al., 2003), account for the ideological asymmetry in responses to low democracy. Each mediator showed an independent indirect effect, both marginal and of comparable size, 
DEMOCRACY AND IDEOLOGY

bequality $=-0.37, \mathrm{SE}=0.19, p=.050, C I_{95}=[-0.74,0.001] ; b_{\text {system justification }}=-0.46, \mathrm{SE}=0.24, p=$

$.051, C_{95}=[-0.92,0.002]$.

\section{Discussion}

Study 2 adds further pre-registered evidence for the prediction shared by our two theoretical lenses: That at least where governments are conservative, liberals will be more distressed than conservatives by signs that their country's democracy is weak. Moreover, this effect emerged even though we were careful to avoid language with unintended liberal connotations, and to describe democratic flaws in ways both liberals and conservatives would recognize.

Study 2 also found that accounting for liberals' tendency to place more value on equality, and to justify the system less, statistically eliminated their stronger reactions. This is consistent with a dispositional account of the asymmetry. Across most times and cultures, liberals value equality more and justify the system less than conservatives (Haidt \& Graham, 2009; Jost et al., 2003), so if those variables are responsible for the asymmetry, we would expect to observe it in most places across the world. At the same time, it could still be that ideologically-relevant situations change how citizens relate to democracy, and in particular cause them to care more or less about it depending on the ideology of the political party in power, above and beyond any dispositional differences. We began to test this question by implementing our paradigm in nonUS countries.

\section{Studies 3a-3c}

Between November 2018 and February 2019, we replicated our quiz game paradigm three times: Once in a non-US country led by a conservative government (the UK under Prime Minister Boris Johnson; Study 3a) and more critically twice in a country led by a liberal 


\section{DEMOCRACY AND IDEOLOGY}

government (Canada under Prime Minister Justin Trudeau; Studies 3b and 3c). Under both our theoretical lenses, we expected the UK sample would show a similar ideological asymmetry to our US samples: The political context was similar in both countries at least in the sense that both were led by conservative governments. For our Canadian samples, we anticipated two possibilities. The dispositional lens predicts that Canadians would show the same ideological asymmetry, with liberals reacting more strongly to news of low democracy in their country. The situational lens instead predicts that the asymmetry would flip: That conservatives would respond more strongly, since in liberal-led Canada it is likely they who feel they have most to lose from a weaker democracy.

Studies $3 \mathrm{a}$ and $3 \mathrm{~b}$ also included control conditions in which we presented participants with negative information about their country that was not about democracy. Though conservatives are more sensitive to negative information in general (Oxley et al., 2008; Shook \& Fazio, 2009), some evidence shows that liberals are more sensitive than conservatives to various country-level threats; for example, growing economic or social inequality (Napier \& Jost, 2008;

Onraet et al., 2017). This liberal sensitivity to country-level threats could account for the ideological asymmetry we found in sensitivity to information about weakening democracy. In contrast, our two theoretical lenses (with the exception of the system justification mechanism under the stable differences rationale) make predictions that are more specific to threats to democracy. Examining responses among participants in the control conditions allowed us to test whether we would see greater liberal sensitivity to all negative information about their country, or only to negative information about its democracy.

We describe Studies 3a and 3b together, given they have similar methods; we then turn to Study 3c, which was a follow-up to Study 3b, whose null findings surprised us given that our 


\section{DEMOCRACY AND IDEOLOGY}

two theoretical rationales each predict a significant effect (albeit in opposite directions). We preregistered methods and analyses for all three studies (3a:

https://osf.io/7mzc6/?view only=f628d36e97294b36a4b6c94b97d4c133, 3b:

https://osf.io/ukba2/?view_only=24d27d9445e64e50be156ea13f2fb2a7, 3c:

https://osf.io/c4b9v/?view_only=fac345ef6b464b59a9d13efe32156b67).

\section{Studies 3a-3b Methods}

Participants. For Study 3a we recruited 502 UK participants from Prolific Academic (www.prolific.co). As pre-registered, we excluded 12 participants who failed two attention checks described below; one additional participant did not provide their political orientation. This left us with a final sample of 489 (69\% female, age $M=38.53, S D=13.18,84 \%$ European descent, political orientation $M=4.63, S D=1.94$ ). For Study $3 \mathrm{~b}$ we recruited 400 Canadians from Prolific Academic. Also as pre-registered, we excluded two participants who failed both attention checks, yielding a final sample of 398 (45\% female, age $M=30.27, S D=9.41$, political orientation $M=4.00, S D=1.93$ ). Both samples received $£ 1.25$ in compensation (for Study $3 b$ participants this translated into approximately \$2.20 CAD).

A first attention check in both studies was a paragraph of instructions asking participants to skip the question that followed and instead enter a specific word into a textbox; a second was a difficult sentence followed by a question about the meaning of that sentence. For both studies, we pre-registered a third check that we accidentally omitted from our survey (see uploaded survey documents at OSF link).

Procedure. Participants first reported their political orientation using the same 10-point scale, and their baseline distress using three items randomly selected for each participant from the set of $\operatorname{six}(3 \mathrm{a}: M=25.29, S D=20.54, \alpha=0.89 ; 3 \mathrm{~b}: M=26.07, S D=20.17, \alpha=0.87)$. Then, 


\section{DEMOCRACY AND IDEOLOGY}

they were randomly assigned to the low democracy quiz game or to a new control quiz game. In Study 3a, this control quiz described participants' country (the UK) as an undesirable holiday destination. In Study 3b, it instead described their country (Canada) as having a weak economy. Participants then completed the post-manipulation distress measure consisting of the remaining three items (3a: $M=26.19, S D=22.11, \alpha=0.90 ; 3 \mathrm{~b}: M=29.23, S D=20.23, \alpha=0.86)$.

Low democracy conditions. Participants in this condition read Study 2's improved definition of democracy and ranked the democracy of their own country (the United Kingdom in 3a, Canada in 3b) against the eight comparison countries we used before (though in Study $3 \mathrm{~b}$ only we replaced Iceland with Japan). At the time of the studies the EIU ranked both the UK (8.53) and Canada (9.15) as full democracies; for the sake of the experiment, we told participants their country's ranking was 7.98 - the US's score from 2017 that we used in previous studies. At the end of the survey, all participants reported how much they agreed with the information they had read about their country ( $1=$ strongly disagree to $7=$ strongly agree $)$. We had also included this question as an exploratory measure in previous studies, allowing us to verify that our manipulation was no less believable now that it involved some deception (see below). As in previous studies, in this condition as well as in the control conditions below, participants learned that they had performed better than $87 \%$ of other participants.

Control condition for Study 3a. As in Study 1's control condition, participants learned about Conde Nast's rankings of countries' desirability as a holiday destination. They then ranked their country (the UK) alongside eight other countries which, contrary to Study 1, were all very popular vacation destinations (Japan, India, Greece, France, Costa Rica, Thailand, Chile, Hungary). Participants then saw from the countries' ostensibly true rankings, as well as from a written message, that their country was a relatively undesirable holiday destination. 


\section{DEMOCRACY AND IDEOLOGY}

Control condition for Study $\mathbf{3 b}$. We adapted a similar format to provide participants criteria for rating the strength of a country's economy, which we attributed to the EIU but had assembled ourselves to sound plausible: (1) Gross National Income, (2) Gross National Product, (3) Gross Domestic Product, (4) Income Index, and (5) Exports and Imports. They then ranked the economic strength of their country (Canada) and the same eight comparison countries that appeared in the low democracy condition. Participants then saw from the countries' ostensibly true rankings, as well as from a written message, that their country's economy was weak. Table 4

presents a summary of methodological differences between all three studies, and feedback messages for all conditions.

Table 4. Summary of Methods in Studies $3 a, 3 b$, and $3 c$

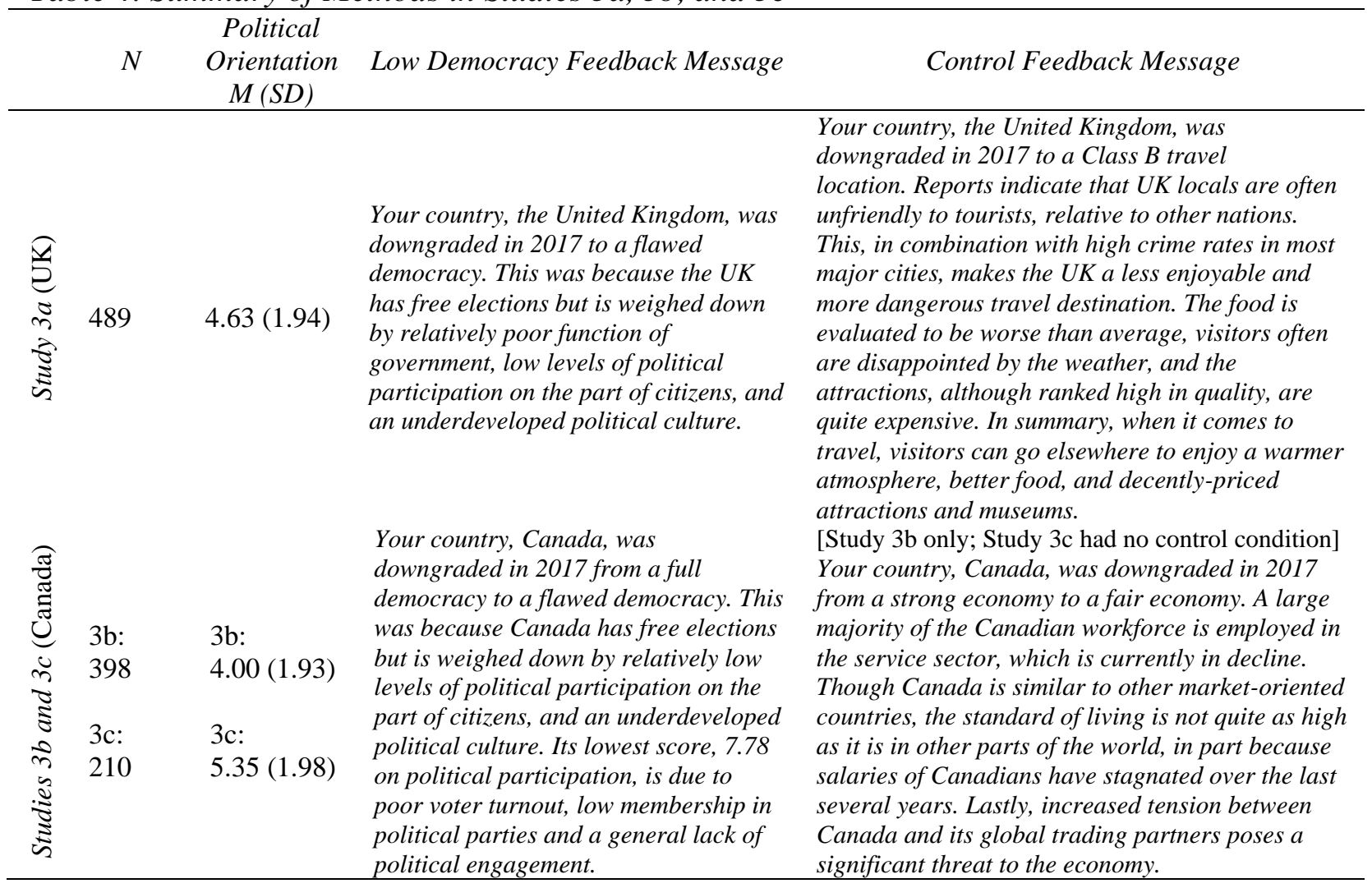

\section{Studies 3a-3b Results}


Did participants believe the low democracy message? Though we did not pre-register these analyses, we confirmed that the deception in this study did not make our manipulation less credible. Low democracy participants generally agreed with the rankings in these $\left(M_{3 a}=4.63, S D\right.$ $\left.=1.24 ; M_{3 b}=5.37, S D=1.10\right)$ and our previous three $\left(M_{1}=5.20 ; S D=1.38 ; M_{S O M}=5.09, S D=\right.$ $\left.1.38, M_{2}=5.15, S D=1.39\right)$. American samples did not differ significantly from Study $3 \mathrm{a}(b=-$ $\left.0.15, t=-1.50, p=.133, C I_{95}=[-0.35,0.04]\right)$ and in $3 b$, if anything Canadians found the feedback more believable than had Americans; $\left.b=0.22, t=2.00, p=.045, C I_{95}=[0.002,0.43]\right)$.

Replications in non-US samples. Our pre-registered plans for both studies were identical: We began by examining the low democracy conditions alone, regressing distress on baseline (0) vs. post-manipulation (1), political orientation (centered), their interactions, and random intercepts for participants (see top half of Table 5, left side of Figure 4, which includes Study $3 \mathrm{c}$ for ease of comparison).

Table 5. Study $3 a$ and $3 b$ simple effects within Low Democracy (Study 3a total N = 241 [481 observations]; Study $3 b$ total $\mathrm{N}=194$ [388 observations]) and Control (Study 3a total $\mathrm{N}=$ 248 [491 observations]; Study $3 b \mathrm{~N}=204$ [408 observations]) conditions.

\begin{tabular}{|c|c|c|c|c|c|c|c|c|}
\hline & \multicolumn{4}{|c|}{ Study $3 \mathrm{a}$} & \multicolumn{4}{|c|}{ Study $3 b$} \\
\hline & $b$ & $t$ & $p$ & $.95 C I$ & $b$ & $t$ & $p$ & $.95 C I$ \\
\hline & \multicolumn{8}{|c|}{ Low democracy } \\
\hline Coefficient & \multicolumn{8}{|c|}{ Full model fixed effects } \\
\hline (Intercept) & 24.08 & 17.45 & $<.001$ & {$[21.38,26.78]$} & 26.69 & 18.67 & $<.001$ & {$[23.89,29.49]$} \\
\hline Political orientation & -0.02 & -0.03 & .975 & {$[-1.46,1.41]$} & -1.07 & -1.40 & .162 & {$[-2.56,0.42]$} \\
\hline Baseline vs. post & 3.09 & 2.46 & .014 & {$[0.63,5.55]$} & 2.13 & 1.41 & .161 & {$[-0.83,5.09]$} \\
\hline Interaction & -1.38 & -2.07 & .040 & {$[-2.69,-0.08]$} & -0.63 & -0.78 & .434 & {$[-2.21,0.95]$} \\
\hline Among & \multicolumn{8}{|c|}{ Simple slopes (change in distress) } \\
\hline Liberals (-1SD) & 5.95 & 3.19 & .002 & {$[2.29,9.60]$} & 3.36 & 1.54 & .125 & {$[-0.92,7.64]$} \\
\hline Conservatives $(+1 \mathrm{SD})$ & 0.59 & 0.34 & .737 & {$[-2.83,4.01]$} & 0.93 & 0.43 & .667 & {$[-3.29,5.14]$} \\
\hline & \multicolumn{8}{|c|}{ Control } \\
\hline Coefficient & \multicolumn{8}{|c|}{ Full model fixed effects } \\
\hline (Intercept) & 32.04 & 9.58 & $<.001$ & {$[25.49,38.58]$} & 25.47 & 17.83 & $<.001$ & {$[22.68,28.27]$} \\
\hline Political orientation & -1.23 & -1.82 & .070 & {$[-2.56,0.09]$} & -0.61 & -0.84 & .403 & {$[-2.02,0.81]$} \\
\hline Baseline vs. post & -7.47 & -2.23 & .026 & {$[-14.02,-0.92]$} & 4.17 & 2.91 & .004 & {$[1.36,6.98]$} \\
\hline Interaction & 1.38 & 2.04 & .043 & {$[0.05,2.71]$} & 1.21 & 1.66 & .098 & {$[-0.22,2.63]$} \\
\hline Among & \multicolumn{8}{|c|}{ Simple slopes (change in distress) } \\
\hline Liberals (-1SD) & -3.75 & -2.05 & .042 & {$[-7.35,-0.16]$} & 1.84 & 0.93 & .355 & {$[-2.06,5.75]$} \\
\hline Conservatives $(+1 \mathrm{SD})$ & 1.61 & 0.83 & .410 & {$[-2.21,5.43]$} & 6.50 & 3.22 & .001 & {$[2.55,10.46]$} \\
\hline
\end{tabular}

Note. There are six missing observations for Study 3 a because three participants reported only their baseline distress and three reported only their post-manipulation distress. 
Figure 4. Low Democracy and Negative Control condition difference scores for Studies $3 a, 3 b$, and $3 c$, broken down by liberal (-1 SD) and conservative (+1 SD) political orientation.

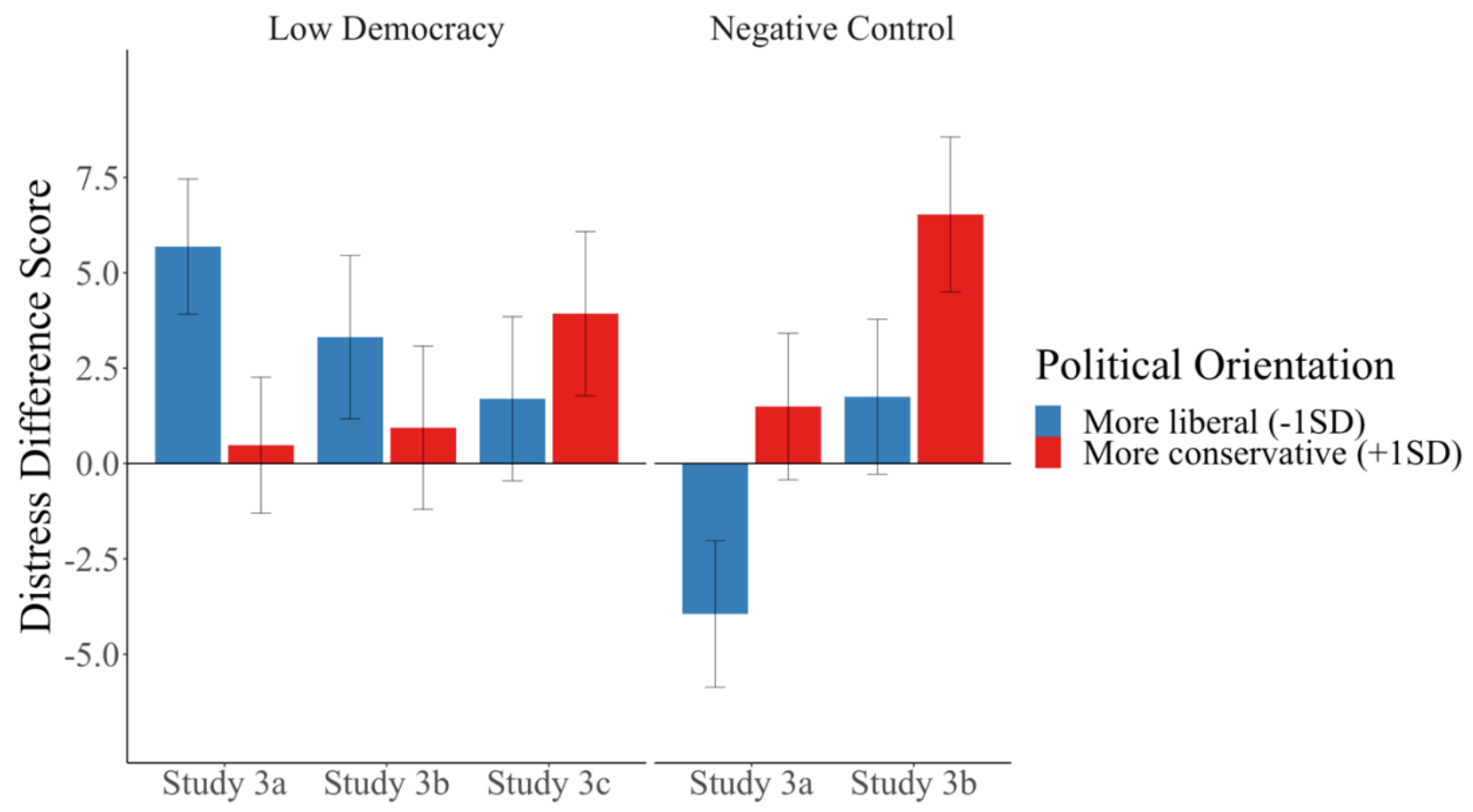

For our UK participants in Study 3a, as in all our prior studies, the significant political orientation $\times$ timing interaction indicated that liberals experienced a greater increase in distress (0.29 standard deviations) than conservatives (0.03 standard deviations). As anticipated under both of our lenses, this conservative-led UK sample looked similar to our US samples with liberals reacting more strongly to information suggesting their countries were low democracy.

For our Canadian participants in Study 3b, the interaction had the same sign (increased distress of 0.17 standard deviations for liberals, 0.05 for conservatives) but was not significant, which initially surprised us. The dispositional rationale gave us no reason to expect the effect would weaken in Canada, but the situational rationale predicted a full reversal, with Canadian conservatives reacting more negatively.

In summary, setting aside participants in the control conditions and examining only participants who underwent a procedure similar to US participants in Studies 1 and 2 (and the 


\section{DEMOCRACY AND IDEOLOGY}

supplemental study), UK participants showed the same asymmetry as had American participants, but Canadian participants showed no asymmetry at all.

Is the asymmetry specific to reactions to democracy? Following our pre-registration, we regressed distress on condition (control $=0$ and experimental $=1$ ), political orientation (centered), timing (baseline $=0$, post-manipulation $=1$ ), all interactions, and random intercepts for participants (see Table 6).

Table 6. Study $3 a$ and $3 b$ full model fixed effects (Study 3a: total $\mathrm{N}=489$ [972 observations]; Study 3b: total $\mathrm{N}=398$ [796 observations]).

\begin{tabular}{lcccccccc}
\hline & \multicolumn{4}{c}{ Study $3 \mathrm{a}$} & \multicolumn{4}{c}{ Study 3b } \\
\hline Coefficients & $b$ & $t$ & $p$ & $.95 C I$ & $b$ & $t$ & $p$ & $.95 C I$ \\
\hline Intercept) & 26.33 & 19.39 & $<.001$ & {$[23.68,28.98]$} & 25.47 & 18.04 & $<.001$ & {$[22.71,28.23]$} \\
Condition & -2.49 & -1.16 & .245 & {$[-6.03,1.53]$} & 1.25 & 0.62 & .538 & {$[-2.70,5.20]$} \\
Political orientation & -1.23 & -1.81 & .071 & {$[-2.56,0.10]$} & -0.61 & -0.85 & .397 & {$[-2.00,0.79]$} \\
Baseline vs. post & -1.07 & -0.82 & .412 & {$[-3.62,1.48]$} & 4.17 & 2.87 & .004 & {$[1.33,7.01]$} \\
Condition $\times$ Baseline vs. post & 4.34 & 2.34 & .020 & {$[0.72,7.96]$} & -2.03 & -0.97 & .331 & {$[-6.10,2.04]$} \\
PO $\times$ Baseline vs. post & 1.38 & 2.12 & .035 & {$[0.11,2.65]$} & 1.21 & 1.64 & .102 & {$[-0.23,2.65]$} \\
Condition $\times$ PO & 1.21 & 1.21 & .227 & {$[-0.74,3.16]$} & -0.46 & -0.44 & .661 & {$[-2.52,1.59]$} \\
Three-way interaction & -2.76 & -2.89 & .004 & {$[-4.63,-0.89]$} & -1.84 & -1.70 & .090 & {$[-3.96,0.28]$} \\
\hline
\end{tabular}

For our UK participants in Study 3a, the three-way interaction between condition, timing, and political orientation was robustly significant and in the direction we anticipated. Table 5 above provides the breakdown of two-way interactions and simple slopes for each condition; as we already reported, the political orientation $\times$ timing interaction emerged in the expected direction when participants encountered negative information about their country's democracy. Its sign was flipped when they instead encountered a different kind of negative information about their country: Liberals had less distress after learning their country was a poor vacation destination but conservatives again showed no change. These results are consistent with the idea that conservatives are generally more reactive to negative information (Carraro et al., 2011; Hibbing \& Alford, 2011; Oxley et al., 2008), and further highlight the unique ideological dynamics at play when it comes to democracy. 


\section{DEMOCRACY AND IDEOLOGY}

For our Canadian participants in Study 3b, the three-way interaction was marginal and also in the expected direction, but it was driven by conservative sensitivity to negative economic information in the control condition (see bottom right of Table 5): Conservatives felt more upset than liberals upon learning that their country's economy was weak, an asymmetry contrary to the non-significant one we observed in response to low democracy. This difference as well may reflect a generally greater conservative sensitivity to bad news (Carraro et al., 2011; Hibbing et al., 2014; Oxley et al., 2008; Shook \& Fazio, 2009), or there may be something about a country's economic success that matters more to (Canadian) conservatives than to (Canadian) liberals. In any case, the only datapoint we have on this question comes from this one Canadian sample, so we hesitate to make too much of it until it can be replicated in future work.

Across these two studies, participants reacted differently to weak democracy than they did to other kinds of negative country-level information. However, the null results from Study 3b's low democracy condition, considered in isolation from any control conditions, fit neither with that general trend, nor with either of our individual lenses. Study $3 \mathrm{c}$ considered two possible explanations for these unexpectedly null results.

\section{Study 3c Methods}

First, and most pertinent to our theorizing, it could be that the political context of a liberal government changed the democratic cost benefit analyses of Canadian liberals and conservatives, enough to counteract but not completely flip a dispositional ideological asymmetry. Second, and more spuriously, the null results could have emerged because our Canadian sample was much more liberal, with a stronger positive skew (0.63) compared to our US and UK samples (Study 1: 0.28; SOM study: 0.23; Study 2: 0.27; Study 3a: 0.33). This skew could have restricted the range within which we had sufficient data to properly estimate effects, leading to the weaker pattern. 


\section{DEMOCRACY AND IDEOLOGY}

To further examine these possibilities, Study $3 \mathrm{c}$ replicated the low democracy condition alone, using a Canadian sample with more wide-ranging and symmetrically distributed political views.

Participants. We recruited a quota sample using the five-point measure of political orientation included in TurkPrime's Prime Panels pre-screening survey. We specified that six percent of participants should identify as very conservative, 24 percent as conservative, 40 percent as moderate, 24 percent as liberal, and six percent as very liberal. Participants were 210 Canadians who passed at least two of the three pre-registered attention checks (the same two as described for Studies 3a-3b, along with a multiple-choice question on which we excluded participants who did not at least slightly agree with the statement "I am a human being") and confirmed they were Canadian nationals (49.9\% women, 58\% European ethnicity, age $M=$ 50.85, $S D=15.85$, political orientation $M=5.35, S D=1.98)$. They completed our study in the context of a larger survey.

Procedure. Participants first reported their political orientation using the same 10-point scale as in previous studies, followed by the baseline measure of distress $\left(M_{\text {pre }}=25.17, S D_{\text {pre }}=\right.$ $24.41, \alpha=0.90)$, with three of our six items randomly selected for each participant. Then, participants played the low democracy quiz game, followed by the remaining three items as a post-manipulation measure of distress $\left(M_{\text {post }}=28.98, S D_{\text {post }}=24.56, \alpha=0.92\right)$.

\section{Study 3c Results}

Our pre-registered analyses followed a familiar strategy: we regressed distress on baseline (0) vs. post-manipulation (1), political orientation (centered), their interactions, and random intercepts for participants (see Table 7; see Figure 4). As with Study 3b's Canadian sample, we again found no ideological difference: The two-way interaction was not significant; instead, 
DEMOCRACY AND IDEOLOGY

distress increased (marginally) across participants regardless of political orientation (increase of 0.07 standard deviations for liberals, 0.16 standard deviations for conservatives).

Table 7. Study 3c full model fixed effects and simple effects (total $\mathrm{N}=210$ [420 observations])

\begin{tabular}{lcccc}
\hline & $b$ & $t$ & $p$ & $.95 C I$ \\
\hline Coefficient & \multicolumn{4}{c}{ Full Model Fixed Effects } \\
\hline (Intercept) & 26.17 & 15.46 & $<.001$ & {$[22.86,29.48]$} \\
Baseline vs. post & 2.81 & 1.85 & .066 & {$[-0.16,5.79]$} \\
Political orientation & -0.26 & -0.29 & .766 & {$[-1.94,1.42]$} \\
Interaction & 0.57 & 0.73 & .465 & {$[-0.95,2.08]$} \\
\hline Among & \multicolumn{5}{c}{ Simple slopes (change in distress) } \\
\hline Liberals (-1 SD) & 1.70 & 0.79 & .430 & {$[-2.52,5.91]$} \\
Conservatives (+1 SD) & 3.93 & 1.83 & .069 & {$[-0.29,8.14]$} \\
\hline
\end{tabular}

\section{Discussion}

In Study 3a, participants from the UK, another conservative-led country, showed the same ideological asymmetry we had found among American participants. That this asymmetry did not emerge (and was even reversed) when we gave participants different negative information about their country suggests that our existing effects do not simply reflect a general liberal sensitivity to country-level threats. These findings further add to our accumulation of evidence for the prediction shared by our dispositional and situational lenses, but do not tease them apart.

Canadian participants in Studies $3 \mathrm{~b}$ and $3 \mathrm{c}$ showed no ideological asymmetry in response to democratic weakness: Both liberals and conservatives found this equally distressing. Though we had not anticipated it in advance, this persistently null pattern in Canada could be the predictable result of our two lenses combined: of liberals being more alarmed by eroding democratic norms due to stable ideologically linked dispositions, but at the same time both groups feeling that a weaker democracy in the context of the current liberal government especially disadvantages conservatives. Null results are difficult to interpret, though; moreover, there could be many other dimensions on which our Canadian samples differ from the US and 


\section{DEMOCRACY AND IDEOLOGY}

UK samples. Study 4 further tested how the ideology of the ruling party might be a situational factor in people's feelings about democracy, exploiting state-level variation in the American cultural context.

\section{Study 4}

Study 4 tests for asymmetries in American liberals' and conservatives' responses to statelevel democracy, in the context of both Democrat- and Republican-led state governments. We conducted the study in May, 2019, recruiting participants specifically from states that were led by either fully liberal or fully conservative state governments (so we could test our moderation hypothesis) but that were balanced in terms of their populations' political orientation (so we could sample comparable numbers of liberals and conservatives). We tested (1) whether the asymmetry predicted by the dispositional lens emerged across participants, this time examining feelings about democracy at the state level, and (2) whether it was strongest in Republican-led states, and either muted or fully reversed in Democratic-led states, as predicted by the situational lens. We pre-registered materials and analysis plans

\section{(https://osf.io/xmpbc/?view_only=014cafc0b47b4ed2bd20c10513a174a5).}

\section{Methods}

Participants. We obtained 982 initial responses on Mturk. As pre-registered, we excluded participants who were not born in the US, or who were neither born nor living in one of our ten target states $(n=269$, even though we had used CloudResearch's pre-screening selection tool to try to only recruit residents in our states of interest). The ten target states included five that were Democratic-led at the time of the survey (Connecticut, Nevada, Oregon, Alaska, South Carolina) and five that were Republican-led at the time of the survey (Iowa, South Dakota, Ohio, Florida, Maine). We selected these ten states because (1) in these states, the same party held 


\section{DEMOCRACY AND IDEOLOGY}

power in the Senate, the House, and the Governor's office, enabling us to cleanly evaluate the role of government ideology, and (2) in these states, the most recent Presidential election had been a close race, which we hoped would lead to a sample with similar numbers of liberals and conservatives. Also as pre-registered, we further excluded participants who did not pass at least two of the same three pre-registered attention checks from Study $3 b(n=49)$, and one participant who answered neither distress measure. Our final sample was 663 (54.4\% women, 36\% European descent, age $M=35.65, S D=11.90$, political orientation $M=4.80, S D=2.58$ ).

Procedure. We first identified, for each participant, which state our manipulation should target. Participants reported their current state of residence, as well as their place of birth. If these answers were both US states, participants further reported which they identified with more. The manipulation targeted participants' state of residence except in cases where a) their birth state was also one of our ten states of interest, and b) they reported identifying with that state as strongly or more strongly than their state of residence; in these cases the manipulation targeted participants' birth state.

Participants then completed our measure of political orientation and our baseline measure of distress $(M=26.55, S D=22.99, \alpha=0.88)$. Then, they played the low democracy quiz game adapted to the state level. Departing from previous studies' EIU criteria, they read about new criteria for democracy that were more relevant to state politics: (1) Electoral oversight, (2) Legislative accountability, (3) Lobbying disclosure, (4) Public access to information, and (5) Ethics enforcement agencies. Similar to previous studies, participants ranked their target state alongside eight others from most to least democratic. One comparison state ranking lower than participants'-Michigan, which had not yet emerged as a contentious battleground state in the 


\section{DEMOCRACY AND IDEOLOGY}

2020 election — while seven ranked higher (Alabama, California, Kentucky, Massachusetts,

Rhode Island, Virginia and Washington).

After seeing the EIU's ostensible rankings, participants read the following:

[Participant's state] was downgraded in 2018 to a flawed democracy. This is because electoral oversight is relatively weak, and public access to information is poor. Though third-party organizations monitor the electoral process, their leadership is not protected from political interference. As a result, state elections are generally more corrupt than in other US states. Compared to other US states, there is little control over lobbyists' donations to parties. Also, many legislative decisions, especially budgetary, are made behind closed doors. The state's ethics enforcement policies are weak, so there is little power to enforce public access to information.

Participants then responded to our post-manipulation distress items $(M=29.40, S D=$ 24.08, $\alpha=0.86$ ), and completed the demographics form and an exploratory measure of their involvement in state politics not relevant to our pre-registered analyses or hypotheses.

\section{Results}

Replicating the ideological asymmetry across the sample. Following our preregistered analysis plan, we first tested whether we observed the ideological asymmetry predicted by the dispositional lens across this entire (American) sample, regarding state-level democracy and without taking into account the ruling party's ideology. We regressed distress on baseline (0) vs. post-manipulation (1), political orientation (centered), their interaction, random intercepts for participants within states, and random intercepts for states $^{3}$ (see Table 8 ). We centered political orientation within states because people living in different political cultures can use this scale with different reference points (Zuell \& Scholz, 2019), but results are the same if we use grand-mean centering.

Table 8. Study 4 model excluding state ideology (total $\mathrm{N}=663$ [1298 observations])

$\begin{array}{llll}b & t & p & .95 \mathrm{CI}\end{array}$

\footnotetext{
${ }^{3}$ In the pre-registration document, we stated we would include random intercepts for subjects within states, and for subjects. This was a typo: It is impossible to include two separate random intercepts for subjects; moreover, the lme 4 code we included in our pre-registration lays out the analysis we describe here.
} 
DEMOCRACY AND IDEOLOGY

\begin{tabular}{lcccc}
\hline Coefficient & \multicolumn{4}{c}{ Full Model Fixed Effects } \\
\hline (Intercept) & 27.21 & 17.43 & $<.001$ & {$[24.12,30.55]$} \\
Baseline vs. post & 2.89 & 3.27 & .001 & {$[1.16,4.62]$} \\
Political orientation & -0.03 & -0.09 & .924 & {$[-0.73,0.66]$} \\
Interaction & -0.85 & -2.49 & .013 & {$[-1.53,-0.18]$} \\
\hline Among & \multicolumn{5}{c}{ Simple slopes (change in distress) } \\
\hline Liberals (-1 SD) & 5.10 & 4.08 & $<.001$ & {$[2.65,7.55]$} \\
\multicolumn{1}{c}{ Conservatives (+1 SD) } & 0.69 & 0.55 & .584 & {$[-1.77,3.14]$} \\
\hline
\end{tabular}

Note. There are 28 missing observations because participants reported only their baseline distress. This larger than usual attrition rate (4\%) prompted us to ensure that these dropout participants did not differ from the remainder in their political orientation $(b=0.17, t=0.35, p=.725)$ or baseline distress $(b$ $=1.82, t=0.41, p=.683)$.

Participants on average were distressed by the information about their state's failing democracy. As in Studies 1-3a, there was a significant political orientation $\times$ timing interaction such that this distress was greater among liberals (-1SD on political orientation; increase of 0.22 standard deviations) than among conservatives (+1SD on political orientation; increase of 0.03 standard deviations).

Comparing Republican- vs. Democratic-led states. We tested whether this interaction was further qualified by the ideology of the state government. We created multilevel models regressing distress on baseline (0) vs. post-manipulation (1), political orientation (centered), state leadership $($ Democrat $=-1$, Republican $=1)$, all interactions, random intercepts for participants within states, and random intercepts for states (see Table 9). The three-way interaction was not significant, though its coefficient held the expected sign.

Table 9. Full model fixed effects (total $N=663$ [1298 observations])

\begin{tabular}{lcccc}
\hline Coefficient & $b$ & $t$ & $p$ & $.95 C I$ \\
\hline Intercept) & 27.63 & 16.39 & $<.001$ & {$[24.45,30.90]$} \\
Baseline vs. post & 2.47 & 2.37 & .018 & {$[0.43,4.50]$} \\
Political orientation & -0.04 & -0.09 & .927 & {$[-0.86,0.78]$} \\
State ideology & -1.27 & -0.75 & .471 & {$[-4.49,1.94]$} \\
Political orientation $\times$ Baseline vs. post & -0.66 & -1.66 & .096 & {$[-1.47,0.12]$} \\
State ideology $\times$ Baseline vs. post & 0.82 & 0.79 & .432 & {$[-1.22,2.85]$} \\
State Ideology $\times$ Political orientation & 0.01 & 0.02 & .983 & {$[-0.81,0.83]$} \\
Three-way interaction & -0.34 & -0.83 & .408 & {$[-1.13,0.46]$} \\
\hline
\end{tabular}




\section{DEMOCRACY AND IDEOLOGY}

In our pre-registration, we had anticipated this possibility: Limitations on the number of available participants from our target states in the subject pool had left us uncertain of whether our sample would have adequate power. For this reason, our pre-registered plan was to run the separate analyses for participants in Republican states and Democratic states regardless of whether we observed a significant interaction. Specifically, our plan was to run the timing $\times$ orientation model described above separately in the two groups of states (see Table 10, Figure 5). Unexpectedly, our sample size for participants living in Democratic states was far smaller than our sample size for participants living in Republican states, which made it an unfair test to merely compare significance levels across the two samples. Therefore, in interpreting our results we also examined the size of the coefficient estimates.

Table 10. Study 4 simple effects within Democratic-led (total $\mathrm{N}=159$ [309 observations]) and Republican-led (total $\mathrm{N}=504$ [989 observations]) states

\begin{tabular}{lcccccccc}
\hline & \multicolumn{4}{c}{ Democratic-led States } & \multicolumn{4}{c}{ Republican-led States } \\
\hline & $b$ & $t$ & $p$ & $.95 C I$ & $b$ & $t$ & $p$ & $.95 C I$ \\
\hline Coefficient & & & \multicolumn{7}{c}{ Full model fixed effects } \\
\hline Intercept) & 29.25 & 7.13 & $<.001$ & {$[21.35,37.15]$} & 26.05 & 20.67 & $<.001$ & {$[23.53,28.83]$} \\
Baseline vs. post & 1.65 & 0.90 & .369 & {$[-1.94,5.24]$} & 3.28 & 3.25 & .001 & {$[1.30,5.26]$} \\
Political orientation & -0.05 & -0.06 & .948 & {$[-1.47,1.37]$} & -0.03 & -0.07 & .942 & {$[-0.82,0.77]$} \\
Interaction & -0.34 & -0.47 & .638 & {$[-1.74,1.06]$} & -1.01 & -2.58 & .010 & {$[-1.78,-0.24]$} \\
\hline Among & & & \multicolumn{7}{c}{ Simple slopes (change in distress) } & \\
\hline$\quad$ Liberals (-1SD) & 2.52 & 0.97 & .331 & {$[-2.55,7.60]$} & 5.89 & 4.13 & $<.001$ & {$[3.09,8.69]$} \\
$\quad$ Conservatives (-1SD) & 0.78 & 0.30 & .766 & {$[-4.34,5.89]$} & 0.67 & 0.47 & .639 & {$[-2.13,3.48]$} \\
\hline
\end{tabular}

Figure 5. Difference scores for US States, broken down by liberal (-1 SD) and conservative $(+1 S D)$ political orientation. 


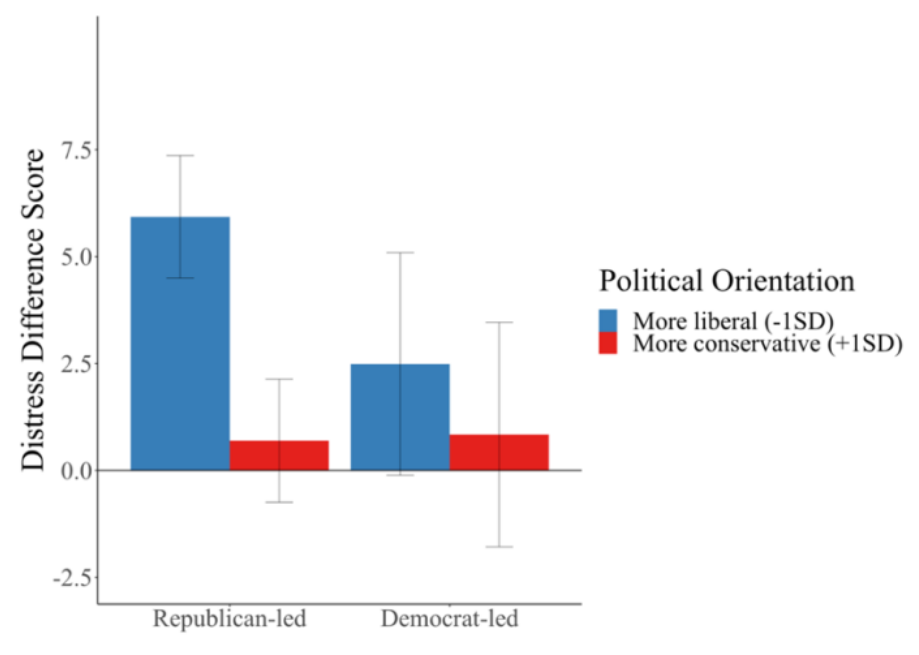

The predicted two-way interaction between political orientation and baseline vs. post measure emerged robustly in Republican-led states (where distress increased by 0.26 standard deviations for liberals, and 0.03 standard deviations for conservatives) but not in Democratic-led states (where the increases were of 0.11 and 0.03 standard deviations, respectively). Moreover, the estimated size of the interaction was almost four times larger in Republican-led states than it was in Democrat-led states, making it unlikely that this difference is merely due to sample size. Instead, these results closely parallel what we observed across Studies 3a-3c, where the familiar ideological asymmetry emerged in conservative-led samples, but neither emerged nor reversed in liberal-led samples.

\section{Discussion}

Learning that their state's democracy was weak was more distressing for liberals compared to conservatives, both across all data and in Republican-led states specifically, a subgroup that dominated our overall sample. But, as we observed when examining country-level democracy, this ideological asymmetry disappeared - its size was much smaller and it was not significant—when we examined a sample whose relevant government was liberal.

This pattern is consistent with a combination of both the dispositional lens (liberals are inherently more disturbed by weaker democracy than conservatives) and the situational lens 
DEMOCRACY AND IDEOLOGY

(people's reactions to a weak democracy depend on who stands to lose more from this state of affairs). At the same time, the pattern itself is not cleanly present in our data, having emerged either in separate studies (Studies 1 through $3 a$ versus $3 b$ and $3 c$ ) or with a non-significant threeway interaction (political orientation $\times$ timing $\times$ state ideology). To shed further light on this issue, we pooled all available data to maximize power, and tested whether we observed a reliable moderating role of governing party's ideology on the asymmetry.

\section{Analysis of Pooled Data}

We pooled the low democracy conditions from Studies 1-4 along with the SOM study (i.e., all available datapoints; these are all the studies we have run examining this research question) to evaluate how the ideological asymmetry in responses to weak democracy is moderated by the political context of the ruling party. This yielded a combined sample of 1909 participants, providing $99 \%$ power to detect even a very small $\left(f^{2}=0.01\right)$ three-way interaction between government ideology, baseline vs. post measure, and political orientation. We also use this pooled sample to examine and report the overall pattern for the cognitive well-being measures we noted above; see SOM for details on these measures' analyses in individual studies.

\section{Method}

Standardizing variables within samples. We standardized the distress indicator within studies to account for differences between studies that could contribute to between-study variation. For example, Study 1 and the SOM study used five items to measure distress whereas subsequent studies used six. We standardized distress within each study across baseline and postmanipulation measures combined; if we had standardized them separately, we would have forced the average change in distress from before to after the manipulation to be zero. 


\section{DEMOCRACY AND IDEOLOGY}

We also standardized our measure of political orientation within study, but for consistency with what we reported above, we preserved Study 4's within-state centering. As above, however, results are essentially the same if we use grand-mean centering.

Additional cognitive DVs. As noted above, in every study we also included two measures related to participants' cognitive well-being: the satisfaction with life scale (SWLS; Diener et al., 1984; e.g., "in most ways my life is close to my ideal"; responses ranging from $1=$ Strongly disagree to $7=$ strongly agree); and a single-item measure assessing appraisals of security: "In terms of your well-being (e.g., how good is your life-how safe and comfortable you feel, and how much you feel you can survive and prosper) where would you place yourself on this scale right now?", with responses ranging from 1=Extremely bad to 10=Extremely good. These constructs are related to well-being, but in a cognitive way, qualitatively different from the affective state of distress (see Diener et al., 1999; Pavot \& Diener, 1993). Individual studies yielded inconsistent findings on these measures; here we test them across all datapoints. For consistency with the distress measure, we standardized them within individual studies.

\section{Results}

Predicting distress. We regressed distress on baseline (0) vs. post-manipulation (1), political orientation (standardized as described above), liberal (-1) vs. conservative (1) country / state government, all two- and three-way interactions, and participants nested within datasets, so that each dataset and each participant within that dataset had its own intercept (Table 11, Figure 6). We did not include random slopes at the level of participants (because each participant had only two datapoints) or at the level of dataset (lme4 cannot nest slopes within dataset and also subjects within dataset).

Table 11. Pooled dataset full model fixed effects and simple effects within Liberal (total $\mathrm{N}=563$ [1117 observations]) and Conservative-led (total $\mathrm{N}=1346$ [2668 observations]) jurisdictions.

$\begin{array}{llll}b & t & p & .95 C I\end{array}$


DEMOCRACY AND IDEOLOGY

\begin{tabular}{|c|c|c|c|c|c|c|c|c|}
\hline \multicolumn{5}{|l|}{ (Intercept) } & -0.06 & -2.56 & .011 & {$[-0.11,-0.01]$} \\
\hline \multicolumn{5}{|l|}{ Baseline vs. post } & 0.15 & 6.35 & $<.001$ & {$[0.10,0.19]$} \\
\hline \multicolumn{5}{|l|}{ Political orientation } & -0.03 & -1.02 & .308 & {$[-0.07,0.02]$} \\
\hline \multicolumn{5}{|l|}{ Government ideology } & -0.03 & -1.24 & .217 & {$[-0.08,0.02]$} \\
\hline \multicolumn{5}{|c|}{ Political orientation $\times$ Baseline vs. post } & -0.07 & -2.94 & .003 & {$[-0.11,-0.02]$} \\
\hline \multicolumn{5}{|c|}{ Government ideology $\times$ Baseline vs. post } & 0.05 & 2.10 & .036 & {$[0.003,0.09]$} \\
\hline \multicolumn{5}{|c|}{ Government ideology $\times$ Political orientation } & 0.02 & 0.79 & .432 & {$[-0.03,0.07]$} \\
\hline \multicolumn{5}{|l|}{ Three-way interaction } & -0.06 & -2.39 & .017 & {$[-0.10,-0.01]$} \\
\hline & \multicolumn{4}{|c|}{ Liberal governments } & \multicolumn{4}{|c|}{ Conservative governments } \\
\hline & $b$ & $t$ & $p$ & $.95 C I$ & $b$ & $t$ & $p$ & $.95 C I$ \\
\hline PO $\times$ Baseline vs. post & -0.01 & -0.32 & .751 & {$[-0.09,0.07]$} & -0.12 & -5.00 & $<.001$ & {$[-0.17,-0.08]$} \\
\hline Among & Simpl & lopes & hange & n distress) & & & & \\
\hline Liberals (-1SD) & 0.11 & 1.93 & .054 & {$[-0.001,0.23]$} & 0.32 & 9.11 & $<.001$ & {$[0.25,0.39]$} \\
\hline Conservatives (+1SD) & 0.09 & 1.48 & .139 & {$[-0.03,0.20]$} & 0.07 & 2.07 & .038 & {$[0.004,0.14]$} \\
\hline
\end{tabular}

Figure 6. Difference scores for left- and right-leaning governments in pooled data broken down by liberal (-1 SD) and conservative (+1 SD) political orientation.

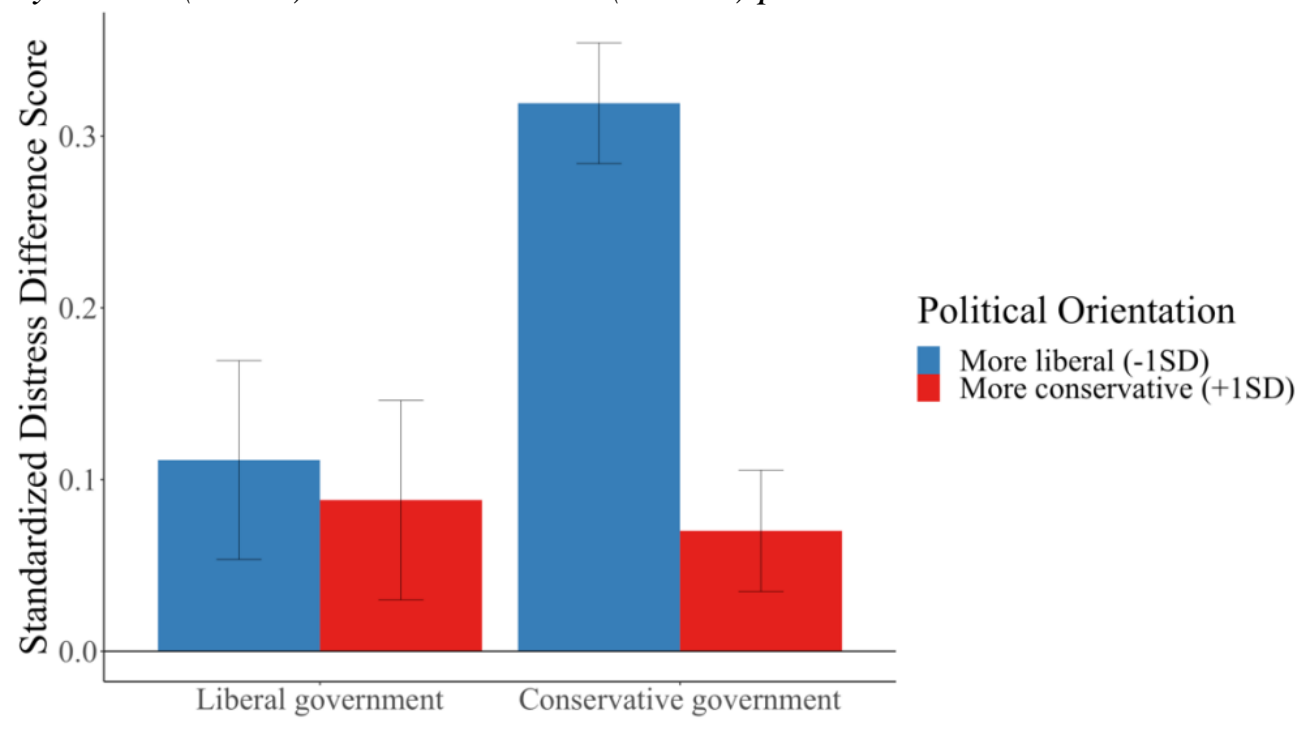

The familiar political orientation $\times$ timing interaction was robust, suggesting that across all available datapoints, liberals were more distressed to learn about low democracy in their jurisdiction, compared to conservatives. A significant three-way interaction indicated this asymmetry was further moderated by government ideology. In conservative-led jurisdictions, the political orientation $\times$ timing interaction was strong: Liberals (-1 SD on political orientation) were more distressed than conservatives (+1 SD on political orientation) by information suggesting their democracy was weak. In liberal-led jurisdictions, this interaction disappeared; instead on average all participants' distress increased when they learned their democracies were 
weak. Because we standardized the distress measures in this study, the simple slope coefficients represent the change in distress expressed in standard deviations (e.g., across studies, distress increased by 0.32 standard deviations among liberals in conservative-led jurisdictions).

Predicting cognitive variables. We used the same models to predict appraisals of security and life satisfaction; see Table 12. First considering security, the political orientation $\times$ timing interaction was significant and in the expected negative direction: Overall liberals reported a greater decrease in felt security than conservatives, upon learning they were living under a weak democracy. However, this asymmetry was not moderated by the ideology of the governing party. For the life satisfaction measure, we found no trace of the asymmetry at either level.

Table 12. Pooled data full model fixed effects for appraised security (total $\mathrm{N}=1909$ [3785 observations]) and Life satisfaction (total $\mathrm{N}=1909$ [3789 observations])

\begin{tabular}{lcccc}
\hline Coefficient & $b$ & $t$ & $p$ & $.95 C I$ \\
\hline Intercept) & \multicolumn{4}{c}{ Appraised security } \\
Baseline vs. post & 0.03 & 1.15 & .249 & {$[-0.02,0.08]$} \\
Political orientation & -0.05 & -3.75 & $<.001$ & {$[-0.08,-0.02]$} \\
State ideology & 0.14 & 5.52 & $<.001$ & {$[0.09,0.18]$} \\
Political orientation $\times$ Baseline vs. post & -0.01 & -0.53 & .599 & {$[-0.06,0.04]$} \\
State ideology $\times$ Baseline vs. post & -0.03 & 2.46 & .014 & {$[0.01,0.06]$} \\
State Ideology $\times$ Political orientation & 0.01 & -0.50 & .820 & {$[-0.03,0.02]$} \\
Three-way interaction & 0.01 & 0.45 & .651 & {$[-0.02,0.03]$} \\
\hline & \multicolumn{4}{c}{ Life satisfaction } \\
\hline Intercept) & 0.01 & 0.21 & .829 & {$[-0.04,0.05]$} \\
Baseline vs. post & 0.001 & 0.06 & .954 & {$[-0.03,0.03]$} \\
Political orientation & 0.13 & 4.91 & $<.001$ & {$[0.07,0.17]$} \\
State ideology & -0.004 & -0.18 & .854 & {$[-0.05,0.04]$} \\
Political orientation $\times$ Baseline vs. post & 0.02 & 0.97 & .332 & {$[-0.02,0.05]$} \\
State ideology $\times$ Baseline vs. post & -0.04 & -2.52 & .012 & {$[-0.07,-0.01]$} \\
State ideology $\times$ Political orientation & 0.01 & 0.33 & .741 & {$[-0.04,0.06]$} \\
Three-way interaction & -0.02 & -0.96 & .337 & {$[-0.05,0.02]$} \\
\hline
\end{tabular}

\section{Discussion}

The pooled analyses yielded four findings. First, across all our data, there was an overall asymmetry between liberals and conservatives in their feelings about low democracy; this is consistent with the dispositional lens. Second, this asymmetry emerged particularly when the governing party was conservative (and presumably liberals had most to lose from weak 


\section{DEMOCRACY AND IDEOLOGY}

democracy); this is consistent with the situational lens. Third, though the asymmetry disappeared, it did not flip into its mirror image when the governing party was liberal (and presumably conservatives had most to lose from weak democracy); this is consistent with the combination of the two lenses: The political context may be layered on top of an asymmetry rooted in dispositional differences between liberals and conservatives. Fourth, these results about how distressed people feel at most only partially extended to cognitive variables.

\section{Study 5}

Wave 6 of the World Values Survey gave us even greater power to examine the pattern we observed and attributed to the combination of our two lenses: We examined the association between people's typical emotional state and a third-party measure of democracy. With this new approach we aimed to complement our controlled lab experiments that examined fluctuations in people's emotional states in direct response to democracy information.

The WVS also offered a useful opportunity to further examine the moderating role of government ideology. We coded each country's government as left- or right-leaning, relative to the that country's own political spectrum. Moreover, we considered a host of person- and country-level variables to help rule out potential confounds in this correlational design.

\section{Methods}

Participants. Wave 6 of the WVS, collected between 2011 and 2014, yielded a sample size of 63,857 with values available for political orientation and for our main dependent variables (happiness and life satisfaction; see SOM section on cognitive variables for analyses with life satisfaction). These participants represented 54 countries.

Measures. We identified or developed measures for our conceptual variables: countrylevel democracy, individual-level political orientation, individual-level emotional state, and 


\section{DEMOCRACY AND IDEOLOGY}

country-level ruling party ideology, and. We also sought potential covariates, and we planned to conduct our analyses both with and without them, for robustness.

Democracy. To assess each country's overall level of democracy, we used data from the EIU's Democracy Index, which is based on over 60 different quantitative indicators. We used the values from 2011-2014, selecting each country's score based on the year of WVS data collection in that country.

Political orientation. To assess respondents' political orientation, we used their selfpositioning on a 10-point scale of general political views ranging from 1 (left) to 10 (right), consistent with our experimental studies $(M=5.75, S D=1.40)$.

Distress. To measure people's typical emotional state, we used an item probing happiness, and kept its inverse coding to parallel our distress measure from prior studies: “Taking all things together, would you say you are..." (1=very happy; 4=not at all happy; $M=$ $3.14, S D=0.74)$. In other words, as in our prior studies, higher scores on this measure indicate greater distress.

Government ideology. To assess each country's governing party, two independent coders evaluated the political party in power in each of the 54 countries involved in WVS wave 6 . They first identified the party in power at the time of data collection, which for different countries occurred at different times between 2011 and 2014. They then coded each party in a binary fashion, as either 'left-leaning' or 'right-leaning' (though in practice they had to add an additional "uncodable" category; see below). Rather than using absolute definitions for the terms left- and right-leaning, coders categorized the current government relative to the country's own political spectrum. For instance, whereas there is debate over whether the Democratic Party in the US is, in absolute terms, left-leaning, centrist, or even right-leaning, there is little debate that, 


\section{DEMOCRACY AND IDEOLOGY}

in the context of the viable options that American voters choose between, it is the more leftleaning. The coders used exclusively academic papers and reports from reputable news outlets to determine each governing party's orientation and resolved any discrepancies through discussion until they reached agreement, which they did in 51 cases. In the three remaining cases, the first author broke the tie.

This final set of codes identified 18 countries led by right-leaning governments at the time of WVS data collection (Armenia, Azerbaijan, Chile, Egypt, Germany, Hong Kong, Malaysia, Mexico, Morocco, Nigeria, Russia, Rwanda, Slovenia, South Korea, Sweden, Taiwan, Turkey, Yemen) and 24 countries led by left-leaning governments (United States, Australia, Bahrain, Belarus, Brazil, Cyprus, Ghana, Iraq, Kyrgyzstan, Netherlands, New Zealand, Pakistan, Palestine, Peru, Philippines, Poland, Romania, South Africa, Spain, Trinidad and Tobago, Tunisia, Uruguay, Uzbekistan, Zimbabwe).

The coders agreed that the twelve remaining countries' governments could not be coded as left- or right-leaning, nine because their ideology was not clearly 'left' or 'right' (Argentina, Colombia, Ecuador, Thailand, Ukraine, India, Algeria, Japan, Estonia), and three because their democracies were too weak to code with confidence (Lebanon, Libya, Kazahkstan). We omit these twelve countries from our analyses involving the government ideology variable, but report in the SOM analyses showing there is no ideological asymmetry within them.

Controls. We gathered nation-level indicators that might covary with a nation's level of democracy or its governing party's ideology (again using indicators from the year that matched the dates during which WVS data were collected in each country): GINI coefficient (World Bank, 2012; 2013; 2014), GDP (World Bank Group, 2012; 2013; 2014; converted to trillions of USD), Government spending as a \% of GDP (The Heritage Foundation, 2012; 2013; 2014), the 


\section{DEMOCRACY AND IDEOLOGY}

education index (Transparency International, 2012; 2013; 2014 figures were not available so we used those from 2013), the corruption index (Transparency International, 2015), and the Human Development Index (United Nations Development Program, 2012; 2013; 2014).

We also gathered individual-level variables from the WVS that might covary with people's political orientation or typical emotional state: age, gender (female $=0$; male $=1$ ), selfreported social class ( $1=$ upper class; $5=$ lower class, reverse-scored), relative household income (reported on a ten-point scale relative to others in the country, $1=$ lower step; $10=$ tenth step), education ( $1=$ no formal education; $9=$ university-level, with degree), and religious attendance (1=More than once a week; $7=$ Never / practically never; reverse-scored). We centered all continuous covariates in the models below.

\section{Results}

Overall ideological asymmetry. We first tested whether, overall, liberals' emotional distress was more strongly related to country-level democracy compared to conservatives'. Table 13 shows the result of our model with the entire sample of 54 countries, both with and without covariates, regressing distress on political orientation (centered within country, for reasons noted above), country-level democracy (centered), their interaction, and random intercepts for country (but not random slopes; including these led to problems with model convergence).

The predicted democracy $\times$ political orientation interaction emerged in the expected direction in both models, indicating that as democracy decreased, distress increased more for liberals than it did for conservatives (see Table 13). The asymmetry emerged across a broad range of countries, each experiencing their own political contexts at the time of data collection; we therefore take it as consistent with the dispositional lens.

Table 13. Study 5 model excluding government orientation both without (total $\mathrm{N}=54$ 
countries [63,857 observations]) and with (total $\mathrm{N}=53$ countries [60,282 observations]) covariates.

\begin{tabular}{|c|c|c|c|c|c|c|c|c|c|c|}
\hline & \multicolumn{5}{|c|}{ Without covariates } & \multicolumn{5}{|c|}{ With covariates } \\
\hline & $\beta$ & $b$ & $t$ & $p$ & $.95 C I$ & $\beta$ & $b$ & $t$ & $p$ & $.95 C I$ \\
\hline (Intercept) & 0.01 & 1.86 & 51.86 & $<.001$ & {$[1.79,1.93]$} & 0.01 & 1.85 & 51.44 & $<.001$ & {$[1.79,1.92]$} \\
\hline Democracy & -0.04 & -0.03 & -1.76 & .085 & {$[-0.07,0.004]$} & -0.10 & -0.04 & -1.33 & .189 & {$[-0.09,0.01]$} \\
\hline Political orientation & -0.06 & -0.02 & -15.56 & $<.001$ & {$[-0.021,-0.017]$} & -0.05 & -0.02 & -12.45 & $<.001$ & {$[-0.02,-0.01]$} \\
\hline Interaction & 0.01 & 0.002 & 2.95 & .003 & {$[0.001,0.003]$} & 0.01 & 0.002 & 2.87 & .004 & {$[0.001,0.003]$} \\
\hline Gender & & & & & & 0.01 & 0.02 & 3.18 & .002 & {$[0.007,0.03]$} \\
\hline Age & & & & & & 0.08 & 0.003 & 18.28 & $<.001$ & {$[0.003,0.004]$} \\
\hline Social class & & & & & & -0.09 & -0.07 & -20.47 & $<.001$ & {$[-0.08,-0.06]$} \\
\hline Income & & & & & & -0.11 & -0.04 & -26.57 & $<.001$ & {$[-0.045,-0.039]$} \\
\hline Education & & & & & & 0.01 & 0.004 & 2.45 & .014 & {$[0.007,0.006]$} \\
\hline Religious attendance & & & & & & -0.04 & -0.01 & -9.42 & $<.001$ & {$[-0.02,-0.01]$} \\
\hline GINI & & & & & & -0.12 & -0.001 & -2.35 & .023 & {$[-0.01,-0.001]$} \\
\hline GDP & & & & & & -0.01 & -0.002 & -0.11 & .910 & {$[-0.03,0.03]$} \\
\hline Government spending & & & & & & 0.01 & 0.001 & 0.19 & .852 & {$[-0.01,0.01]$} \\
\hline Education index & & & & & & 0.01 & 0.04 & 0.05 & .958 & {$[-1.18,1.25]$} \\
\hline Corruption index & & & & & & -0.02 & -0.001 & -0.24 & .814 & {$[-0.006,0.005]$} \\
\hline HDI & & & & & & 0.04 & 0.18 & 0.26 & .796 & {$[-1.09,1.45]$} \\
\hline Among & & & & Simpl & lopes linking der & locracy & to emotio & nal state & & \\
\hline Liberals (-1SD) & -0.09 & -0.04 & -2.00 & .051 & {$[-0.07,-0.001]$} & -0.11 & -0.04 & -1.44 & .157 & {$[-0.09,0.01]$} \\
\hline Conservatives (-1SD) & -0.08 & -0.03 & -1.51 & .137 & {$[-0.06,0.008]$} & -0.09 & -0.03 & -1.23 & .227 & {$[-0.09,0.02]$} \\
\hline
\end{tabular}

Note. Here, but not in Studies 1-4, we report both standardized and unstandardized regression coefficients. Our experimental evidence shows distress predicted from a dummy-coded variable (pre to post) which, if standardized, would not be interpretable.

Moderation by party ideology. We next tested whether this asymmetry was more

pronounced in countries with right-leaning governments, consistent with Studies 3a through 4 and with a current political moment explanation. For these analyses, we examined only the 42 countries we successfully coded as having either left-leaning or right-leaning governments. We used the same model, adding right- or left-leaning party orientation (effect coded $-1=$ left, $1=$ right) and its interactions (see Table 14 and Figure 7, which depicts the simple slopes).

Table 14. Study 5 full model fixed effects and simple effects in countries with right-leaning (with [without] covariates: 18 [17] countries; 20,629 [19,737] observations) and left-leaning governing party (with [without] covariates: 24 [24] countries; 28,634 [26, 736] observations).

\begin{tabular}{|c|c|c|c|c|c|c|c|c|c|c|}
\hline & \multicolumn{5}{|c|}{ Without covariates } & \multicolumn{5}{|c|}{ With covariates } \\
\hline & $\beta$ & $b$ & $t$ & $p$ & $.95 C I$ & $\beta$ & $b$ & $t$ & $p$ & $.95 C I$ \\
\hline Coefficient & \multicolumn{10}{|c|}{ Full model fixed effects } \\
\hline (Intercept) & 0.01 & 1.86 & 42.03 & $<.001$ & {$[1.78,1.95]$} & 0.03 & 1.87 & 40.79 & $<.001$ & {$[1.79,1.95]$} \\
\hline Democracy & -0.10 & -0.04 & -1.74 & .089 & {$[-0.08,0.003]$} & -0.09 & -0.03 & -0.89 & .378 & {$[-0.10,0.03]$} \\
\hline Political orientation & -0.06 & -0.02 & -14.28 & $<.001$ & {$[-0.023,-0.018]$} & -0.05 & -0.02 & -11.56 & $<.001$ & {$[-0.02,-0.01]$} \\
\hline Party ideology & 0.01 & 0.01 & 0.17 & .865 & {$[-0.08,0.09]$} & 0.02 & 0.01 & 0.27 & .785 & {$[-0.07,0.10]$} \\
\hline Democracy $\times$ PO & 0.01 & 0.002 & 2.96 & .003 & {$[0.001,0.003]$} & 0.01 & 0.002 & 2.77 & .006 & {$[0.001,0.003]$} \\
\hline Democracy $\times$ Party ideology & -0.04 & -0.02 & -0.78 & .437 & {$[-0.06,0.02]$} & -0.06 & -0.02 & -1.07 & .294 & {$[-0.06,0.02]$} \\
\hline PO $\times$ Party ideology & -0.01 & -0.005 & -3.25 & .001 & {$[-0.01,-0.002]$} & -0.01 & -0.004 & -2.45 & .014 & {$[-0.01,-0.001]$} \\
\hline Three-way interaction & 0.01 & 0.002 & 3.33 & $<.001$ & {$[0.001,0.004]$} & 0.01 & 0.002 & 2.50 & .013 & {$[0.000,0.003]$} \\
\hline Gender & & & & & & 0.01 & 0.02 & 2.98 & .003 & {$[0.01,0.03]$} \\
\hline Age & & & & & & 0.08 & 0.003 & 15.92 & $<.001$ & {$[0.003,0.004]$} \\
\hline
\end{tabular}




\section{DEMOCRACY AND IDEOLOGY}

\begin{tabular}{|c|c|c|c|c|c|c|c|c|c|c|}
\hline \multirow{2}{*}{\multicolumn{6}{|c|}{ Social class }} & \multirow[b]{2}{*}{-0.09} & \\
\hline & & & & & & & -0.06 & -16.39 & $<.001$ & {$[-0.07,-0.06]$} \\
\hline Income & & & & & & -0.14 & -0.05 & -25.42 & $<.001$ & {$[-0.05,-0.04]$} \\
\hline Education & & & & & & 0.01 & 0.002 & 1.34 & .179 & {$[-0.001,0.01]$} \\
\hline Religious attendance & & & & & & -0.04 & -0.01 & -7.58 & $<.001$ & {$[-0.02,-0.01]$} \\
\hline GINI & & & & & & -0.15 & -0.01 & -2.22 & .034 & {$[-0.01,-0.001]$} \\
\hline GDP & & & & & & -0.002 & -0.001 & -0.03 & .975 & {$[-0.03,0.03]$} \\
\hline Government spending & & & & & & 0.06 & 0.004 & 0.83 & .411 & {$[-0.005,0.01]$} \\
\hline Education index & & & & & & -0.06 & -0.29 & -0.34 & .739 & {$[-1.79,1.21]$} \\
\hline Corruption index & & & & & & -0.09 & -0.003 & -0.74 & .463 & {$[-0.01,0.004]$} \\
\hline \multirow[t]{2}{*}{ HDI } & & & & & & 0.10 & 0.52 & 0.59 & .557 & {$[-1.00,2.03]$} \\
\hline & \multicolumn{10}{|c|}{ Right-leaning governing party } \\
\hline Democracy $\times$ PO & 0.03 & 0.004 & 4.41 & $<.001$ & {$[0.002,0.006]$} & 0.02 & 0.004 & 3.72 & $<.001$ & {$[0.002,0.006]$} \\
\hline Among & \multicolumn{10}{|c|}{ Simple slopes linking democracy to emotional state } \\
\hline Liberals (-1SD) & -0.18 & -0.06 & -1.74 & .101 & {$[-0.13,0.01]$} & -0.40 & -0.14 & -1.66 & .131 & {$[-0.27,-0.01]$} \\
\hline \multirow[t]{2}{*}{ Conservatives (-1SD) } & -0.12 & -0.04 & -1.18 & .255 & {$[-0.11,0.03]$} & -0.04 & -0.12 & -1.46 & .179 & {$[-0.25,0.005]$} \\
\hline & \multicolumn{10}{|c|}{ Left-leaning governing party } \\
\hline Democracy $\times$ PO & -0.002 & -0.003 & -0.27 & .789 & {$[-0.002,0.002]$} & 0.001 & 0.0002 & 0.17 & .867 & {$[-0.002,0.002]$} \\
\hline Among & \multicolumn{10}{|c|}{ Simple slopes linking democracy to emotional state } \\
\hline Liberals (-1SD) & -0.05 & -0.02 & -0.81 & .427 & {$[-0.07,0.03]$} & 0.05 & 0.02 & 0.38 & .708 & {$[-0.06,0.09]$} \\
\hline Conservatives (-1SD) & -0.06 & -0.02 & -0.86 & .398 & {$[-0.07,0.03]$} & 0.05 & 0.02 & 0.40 & .695 & {$[-0.06,0.09]$} \\
\hline
\end{tabular}

In both models, the same democracy $\times$ orientation interactions emerged; this replication in a different subset of data is a sign of the robust predictive power of the dispositional lens. The three-way interactions also emerged with the expected sign: The familiar orientation $x$ democracy interaction was present where governments were right-leaning, but not where they were left-leaning. In this latter case, as in our previous studies, there was no mirror-image asymmetry, rather conservatives and liberals under liberal governments looked similar.

Figure 7. Coefficient linking democracy with distress for conservative (+1 SD) and liberal (-1 SD) participants within countries with Right-leaning parties and Left-leaning parties 


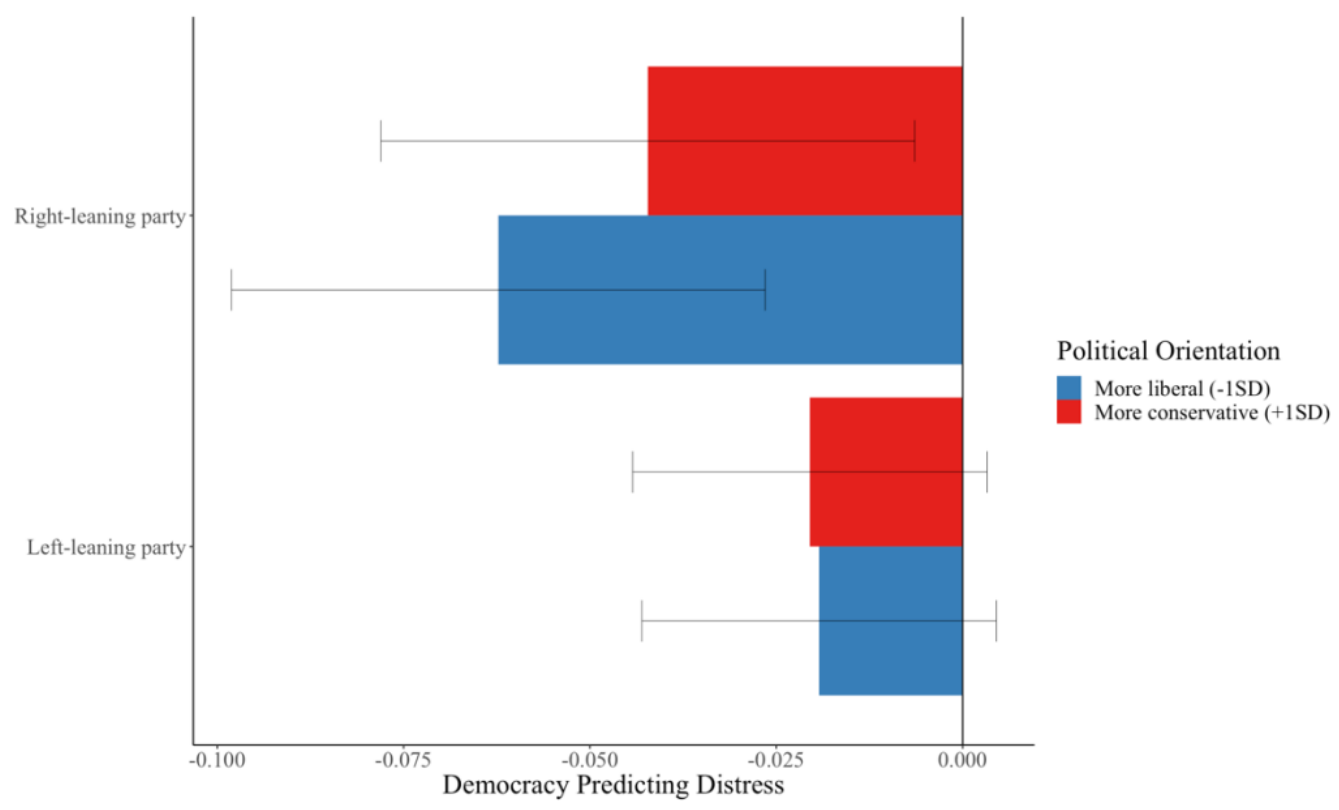

\section{Discussion}

Study 5's findings align remarkably well with those of our pre-registered lab studies. Even though Study 5 used a very different method-large-scale cross-national survey data alongside third-party assessments of democracy, we once again found that liberals' compared to conservatives' emotional state is more closely linked with their country's degree of democracy. Moreover, coders' ratings of government ideology conceptually replicated our pooled analyses: This ideological asymmetry was robust in nations with right-leaning governments, but eliminated in nations with left-leaning governments.

These data ultimately support a combination of our two theoretical lenses. There is a culturally broad trend whereby conservatives seem less distressed by democratic weakness; because this trend emerges across a wide range of countries and contexts we interpret it as reflecting dispositional factors. But this trend is moderated by whose values the current government best supports, suggesting there is a situational or contextual component as well. Overall it would seem people's relationship to democracy relies on the interplay of situational variables with enduring dispositional differences between liberals and conservatives. 


\section{General Discussion}

The seven studies we report here examine the global trend toward democratic decline through a psychological approach. We developed and tested predictions using two contrasting theoretical lenses — one dispositional and one situational—regarding how ideology would factor into reactions to democratic decline. Both lenses predicted that when conservative leaders are in charge, liberal citizens are more disturbed than their conservative counterparts by the prospect of weakness in their nation's democracy; we found support for this prediction in America, in the UK, and in conservative-led US states (Study 1, SOM study, Study 2, Study 3a, Study 4). We found further support for the unique predictions of each of our individual lenses. On the one hand, the asymmetry was mediated by valuing equality and justifying the system, two individual traits that reliably distinguish between liberals and conservatives across time and geography (Study 2). Moreover, the same asymmetry emerged across all available World Values Survey data (Study 5), and we found no case where it reversed: Where conservatives were more distressed by low democracy than liberals. Together, these findings support the idea that there is a fundamental, dispositional difference in how liberals versus conservatives feel about democracy.

On the other hand, we did find that the political context could eliminate, though not invert, this widespread ideological asymmetry: In jurisdictions led by liberal governments, liberals and conservatives had similar emotional responses to democratic weakness (Studies $3 \mathrm{~b}$ and 3c, Study 4, Study 5). We tested the moderating role of government ideology in three ways: In Study 4, in an internal meta-analysis, and in the WVS data. In two out of three analyses, the three-way interaction between individual political orientation, level of democracy, and government ideology, was significant. These findings support the idea that people's feelings 
DEMOCRACY AND IDEOLOGY

about democracy are sensitive to contextual factors, and that they may feel especially attached to democracy when they disagree with current political leaders. In particular, our findings suggest that both liberals and conservatives are especially seized with the importance of democracy, relative to their respective baselines, when they need it to change the current status quo (see McCoy et al., 2020).

\section{Theoretical Implications}

Towards a combined dispositional-situational psychology of democracy. When we began this program of research, we viewed the dispositional and situational lenses as offering conflicting predictions, but our accumulated findings forced us to reconsider how they might instead both hold some truth. We note that we only reached the conclusions we did by considering how our original effects might be specific to a particular sociopolitical context. We hope that this represents only a first step, a starting point from which we and other political psychologists can collaborate with political scientists and scholars from other disciplines to further the question of who supports democracy (see also Frimer et al., 2017; Jost et al., 2020; Proch et al., 2019).

Returning to people's feelings about democracy, our two-lens theoretical approach may prove generative in future research on this question. We identified two relevant dispositions - the value of equality and system justification — but others may exist. As one obvious example, to the extent that authoritarianism is a personality trait disproportionately present on the political right, it may contribute as well. Future research might also consider ideological differences in interpersonal trust (Balliet et al., 2018), faith in experts (Gauchat, 2012; Motta, 2018), patriotism (Schatz et al., 1999), or perhaps elitist beliefs, which have not yet to our knowledge been examined as correlates of ideology. 


\section{DEMOCRACY AND IDEOLOGY}

Conversely, we identified the ideology of the governing party as one contextual contributor, but there are likely others. For instance, another contextual factor that we have not considered here is political polarization. Many argue that polarization motivates people to subvert democratic norms (Graham \& Svolik, 2020; Iyengar, Sood, \& Lelkes, 2012; McCoy et al., 2020), through multiple channels. News and social media outlets will pit opposing political factions against each other, exaggerating their differences, and raising the stakes on the issues that divide them (Finkel et al., 2020; McCoy, Rahman, \& Somer, 2018), such that sacrificing democracy may seem to viewers like a reasonable price to pay. Partisans perceive the other side to be increasingly hostile towards them, which in turn predicts support for undemocratic strategies (Moore-Berg et al., 2020). Connecting to our theoretical perspective, we speculate that as conflict between warring political factions seems less tractable, the benefits of democracy pale in comparison to the increasing urgency of protecting the country from the lunacy of one's opponents.

Symmetries and asymmetries. Our findings are compatible with the established perspective that dispositional differences drive some ideological asymmetries. For example, some scholars argue that liberals and conservatives have fundamentally different moral priorities (e.g., Graham et al., 2009) that reflect universal and stable patterns in their intuitions (Graham et al., 2011). Other scholars argue that conservatives are especially susceptible to motivated cognition, and in particular more motivated to justify the status quo (Jost et al., 2003). Still others show that conservatives are fundamentally more capable of prejudice, social dominance (for a review see Sibley \& Duckitt, 2008), and political violence (Webber et al., 2020). The studies we describe here support the general notion that ideological asymmetries can be driven by ideologically linked dispositions, in particular those documented by Moral Foundations theorists 


\section{DEMOCRACY AND IDEOLOGY}

and by System Justification theorists. Although these two theoretical perspectives often conflict (e.g., Haidt \& Graham, 2009; Kugler, Jost, \& Noorbaloochi, 2014), our findings point to ways in which they may sometimes be aligned.

Our original theorizing had also connected with counterarguments against claims of ideological asymmetry. Some argue that dangerous radicalism and political intolerance are endemic at both ends of the political spectrum, not just the conservative one (Brandt et al., 2014; Chambers, Schlenker, \& Collisson, 2013; Crawford \& Pilanski, 2014). Like some conservatives, some liberals may be authoritarian (Costello et al., 2020). Both the left and right may be biased and motivated (Ditto et al., 2019; Uhlmann et al., 2009), and both groups will shift their perceptions of whether procedures are fair depending on whether they produced the desired outcome (Skitka, 2002; Skitka \& Mullen, 2002). Drawing on these positions, we argued that, likewise, liberals and conservatives might feel similarly upset about weak democracy given that they generally disagreed with their country's leaders.

Our studies in no way supported this symmetry at the level of observable outcomes. In considering how, if at all, our findings could be reconciled with the ideological symmetry perspective, we offer two thoughts. First, some might consider that effects which are similar in direction, if not in magnitude, could still warrant the label symmetry. Applied to our context, this could mean that, just as we find liberals are more upset by low democracy when governments are conservative, it is also true that conservatives are similarly more upset by low democracy when governments are liberal, but to a lesser extent such that the effect size was too small to detect in our samples. We consider this unlikely, but given that the absence of statistical significance is difficult to interpret, we note it as theoretically possible. 


\section{DEMOCRACY AND IDEOLOGY}

Second, it could be that there is symmetry at the level of process, rather than outcome, and that this potentially symmetrical process is combined with other, asymmetrical processes or outcomes. That is, it may be that having one's own party in power reduces everyone's distress about low democracy, but that distress is minimal to begin with among conservative citizens, leading to something of a floor effect. Under this interpretation, if one could induce conservatives to strongly value democracy, then they too might show that value primarily when the party they oppose is in power. Our studies offer no direct evidence for this, but we note there is some precedent for considering this combination of processes. For example, one paper argues that while liberals and conservatives are symmetrically (and, they argue, equally) driven to discriminate against those who violate their respective values, the content of those values asymmetrically attenuates the expression of discrimination among liberals while exacerbating it among conservatives (Wetherell, Brandt, \& Reyna, 2013).

On authoritarianism. Questions around authoritarianism have recurred throughout this article. In the introduction we noted that our findings could align with perspectives that authoritarianism exists more on the political right (Altemeyer, 1981; Nilsson \& Jost, 2020), or with perspectives that there are similar levels of authoritarianism on both sides depending on the nature of the authority in question (Conway et al., 2018; Costello et al., 2020). Instead, our results fell somewhere in the middle, and in particular our null results under liberal governments conflict with both sets of findings.

First, they conflict with papers maintaining that conservatives are in general more authoritarian: We consistently found nothing of the sort when governments were liberal. Perhaps the authoritarian asymmetry papers did not attend with sufficient nuance to differences across time and place under different leadership. 


\section{DEMOCRACY AND IDEOLOGY}

But second, our null results under liberal governments also conflict with authoritarian symmetry papers. Prior papers found that liberals more than conservatives endorse undemocratic (specifically, authoritarian) principles in support of anti-establishment revolutionaries, environmentalists, civil rights activists, and scientific authorities (Conway et al., 2018; Costello et al., 2020; Frimer, Gaucher, \& Schaefer, 2014). In contrast, we found no indication that liberals cared less about democracy in support of liberal governments. In reconciling this apparent conflict, we highlight one difference between our work and the authoritarian symmetry papers: Liberal politicians are typically not scientists or activists, and most governments are not made up of true revolutionaries (Nilsson \& Jost, 2020). This raises the possibility that, if a ruling liberal government was made up of these kinds of individuals, we might find liberal citizens acting blasé about weak democracy, and conservatives experiencing distress.

\section{Broader Implications}

Our results depict liberals as relatively more invested in democracy, compared to conservatives. At the same time, a few different value systems could underlie this relative difference. First, liberals and conservatives might place equal absolute value on democracy, but conservatives more than liberals might place even greater value on certain other principles. This would fit with research showing that conservatives consider more different moral foundations than liberals (Graham et al., 2009).

Second, it possible that liberals do value democracy more, in absolute terms, than conservatives, perhaps in part because as a general rule, democracy may offer more benefits to liberal causes than to conservative causes. Given the interconnections between liberals' values, equality and democracy, it does seem at the very least likely that a stronger democracy would promote greater equality, in line with liberal priorities. 


\section{DEMOCRACY AND IDEOLOGY}

Or third, it might be that conservatives have less investment in democracy right now in its current manifestation, but that this is subject to change. One version of this interpretation is that there may be global trends currently - that is, a context that envelops most of the present world - that makes democracy more instrumental for liberal rather than conservative priorities. For example, it is a relatively new development in America and other European countries that right-wing political parties express less commitment to key democratic principles (Drutman, 2021; Lührmann et al., 2021). Another version considers that democracy itself may take other forms at other times. Most modern democracies place limitations on pure majority-rules democracy so as to protect every citizens' rights and liberties (Freedom House, 2021). Currently accepted definitions of democracy include these limitations (Dahl, 1971; Freedom House, 2019; Zakaria, 1997), and we referenced them in the definitions we provided participants in our studies. However, there may come a time in the future, or have been times in the past, when societies construed democracy more narrowly (see Schumpeter, 1942). If democracy comes to mean something different, this could shift how well it matches liberal versus conservative values, or how instrumental it is for their priorities.

\section{Unanswered Questions}

The present findings open the door to future research exploring more deeply how ideology factors into people's feelings about democracy. We offer a few examples here. First, as we just noted, past or future definitions of democracy may incorporate a different set of components that appeal differentially to liberals and conservatives. Even among the components most commonly referred to today-individual liberties, freedoms, the rule of law, and free and fair elections - there may be different associations with ideology. Future research could deconstruct the definition of democracy to further establish the pattern of relationships. 


\section{DEMOCRACY AND IDEOLOGY}

A similar deconstruction might be applied to the concept of political ideology. We measured this variable with a single holistic item, considering the left-right dimension that is often considered primary (Bobbio, 1996; Jost, 2009). But it is possible to consider more complex forms of political ideology, and those who identify with either side of that spectrum are not perfectly homogeneous groups. To give just one example, Libertarians often affiliate with the American right (as in the Tea Party movement; Wilson \& Burack, 2012) but do not endorse the binding moral foundations of authority, purity, and loyalty (Haidt, Graham, \& Joseph, 2009; Iyer et al., 2012). Libertarians might be more invested in democracy than most conservatives, perhaps because the value they place on equality is less diluted by the binding moral foundations, or because they resent any impositions on freedom and are highly invested in preventing authoritarianism (see Narveson, 2001; Nolan, 1971; Nozick, 1974). Democratic backslides could be particularly distressing to them-perhaps even compared to liberals.

Another question for future research is whether the dispositional asymmetry in people's (at least relative) feelings about democracy translates into an asymmetry in the drive to protect it. Given that emotions motivate political action (Iyer, Schmader, \& Lickel, 2007; Jost, Becker, \& Osborne, 2017; Osborne et al., 2019) liberals should more strongly defend democracy than their conservative counterparts. Conversely, liberal politicians should be less willing to use undemocratic strategies to achieve their goals, weakening their chances against opponents who may be more willing to use any means necessary. At the same time, feelings and attitudes do not always drive behavior (see Ajzen, 1991; see also Kollmuss \& Agyeman, 2002), so future research examining meaningful actions could offer better insights into these questions. Moreover, our theorizing implies that, to bolster people's (and maybe even political leaders') 


\section{DEMOCRACY AND IDEOLOGY}

willingness to stand up for democracy, effective interventions could target liberals' and conservatives' sense that democracy helps promote their other ideological interests.

Another consideration is whether our reliance on online samples impacts the quality and generalizability of our research. Online data collection platforms tend to yield more diverse and representative samples (Buhrmester, Kwang, \& Gosling, 2011), we used samples from multiple pools including the higher quality Prolific Academic (Palan \& Schitter, 2018; Peer et al., 2017), and made an effort to control data quality with pre-registered attention checks (Oppenheimer, Meyvis, \& Davidenko, 2009). At the same time, frequent internet users have a different personality profile than less frequent users (Goodman, Cryder, \& Cheema, 2013), and attention is typically lower than in laboratory settings (Chmielewski \& Kucker, 2020; Goodman et al., 2013; Paolacci \& Chandler, 2014; Oppenheimer et al., 2009). Future research might extend our findings to other populations; in particular perhaps sampling politicians themselves, whose responses may be informative of leaders' motivations to defend democratic values.

A final limitation concerning the replicability of this research is Study 4's failure to uncover a significant three-way interaction, which limits our capacity to interpret the moderating role of the government's ideology (see Cohen, 1994; Wagenmakers, 2007). This effect should be considered alongside our internal meta-analysis and WVS analyses, which do show that threeway interaction. Thus, on balance we provide more evidence for than against the idea that government's ideology moderates the ideological difference in reactions to low democracy. At the same time, this evidence draws much more strongly on country-level evidence than on statelevel evidence. Future work may further explore similarities and differences in the how people's ideology manifests in the context of different levels of politics.

\section{Conclusion}




\section{DEMOCRACY AND IDEOLOGY}

Individual liberties, freedoms, the rule of law, and the ability to participate in free and fair elections are in jeopardy from global democratic backslides (Diamond, 2015b; EIU, 2019; Fandos \& Michael, 2019; Freedom House, 2021). Citizens around the world declare their support for democracy (Pew Research Center, 2017a) yet our studies suggest that people's feelings about democracy vary along with their beliefs and become less ardent when it serves them. People have fled their homes, fought in wars, risked arrest or worse - to find and secure their access to democracy. But when it starts to erode, it may only sometimes and only to some be worth protecting. 


\section{References}

Adorno, T., Frenkel-Brenswik, E., Levinson, D. J., \& Sanford, R. N. (1950). The authoritarian personality. New York: Harper and Row (pp. 228).

Ajzen, I. (1991). The theory of planned behavior. Organizational behavior and human decision processes, 50(2), 179-211.

Altemeyer, B. (1981). Right Wing Authoritarianism. Winnipeg: University of Manitoba Press.

Badaan, V., \& Jost, J. T. (2020). Conceptual, empirical, and practical problems with the claim that intolerance, prejudice, and discrimination are equivalent on the political left and right. Current Opinion in Behavioral Sciences, 34, 229-238. https://doi.org/10.1016/j.cobeha.2020.07.007

Balliet, D., Tybur, J. M., Wu, J., Antonellis, C., \& Van Lange, P. A. M. (2018). Political Ideology, Trust, and Cooperation: In-group Favoritism among Republicans and Democrats during a US National Election. Journal of Conflict Resolution, 62(4), 797-818. https://doi.org/10.1177/0022002716658694

Baron, J., \& Jost, J. T. (2019). False Equivalence: Are Liberals and Conservatives in the United States Equally Biased? Perspectives on Psychological Science, 14(2), 292-303. https://doi.org/10.1177/1745691618788876

Barro, R. J. (1996). Determinants of economic growth: a cross-country empirical study. National Bureau of Economic Research.

Bem, D. J., \& Allen, A. (1974). On predicting some of the people some of the time: The search for cross-situational consistencies in behavior. Psychological Review, 81(6), 506-520. https://doi.org/10.1037/h0037130

Berlin, I. (1969). Two concepts of liberty. Berlin, i, 118(1969), 172. 


\section{DEMOCRACY AND IDEOLOGY}

Bermeo, N. (2016). On democratic backsliding. Journal of Democracy, 27(1), 5-19. https://doi.org/10.1353/jod.2016.0012

Bobbio, N. (1996). Left and right: The significance of a political distinction. University of Chicago Press.

Brandt, M. J., Reyna, C., Chambers, J. R., Crawford, J. T., \& Wetherell, G. (2014). The IdeologicalConflict Hypothesis: Intolerance Among Both Liberals and Conservatives. Current Directions in Psychological Science, 23(1), 27-34.

Brock, D. (2005). The Republican noise machine: Right-wing media and how it corrupts democracy. Three Rivers Press (CA).

Buhrmester, M., Kwang, T., \& Gosling, S. D. (2011). Amazon's mechanical Turk: A new source of inexpensive, yet high-quality, data? Perspectives on Psychological Science, 6(1), 3-5. https://doi.org/10.1177/1745691610393980

Carraro, L., Castelli, L., \& Negri, P. (2016). The hand in motion of liberals and conservatives reveals the differential processing of positive and negative information. Acta Psychologica, 168, 78-84. https://doi.org/10.1016/j.actpsy.2016.04.006

Carney, D. R., Jost, J. T., Gosling, S. D., \& Potter, J. (2008). The secret lives of liberals and conservatives: Personality profiles, interaction styles, and the things they leave behind. Political Psychology, 29(6), 807-840.

Chambers, J. R., Schlenker, B. R., \& Collisson, B. (2013). Ideology and prejudice: The role of value conflicts. Psychological science, 24(2), 140-149.

Citrin, J., Schickler, E., \& Sides, J. (2003). What if everyone voted? Simulating the impact of increased turnout in Senate elections. American Journal of Political Science, 47(1), 75-90.

Cohen, J. (1994). The earth is round (p<. 05). American psychologist, 49(12), 997. 


\section{DEMOCRACY AND IDEOLOGY}

Crawford, J. T., \& Pilanski, J. M. (2014). Political intolerance, right and left. Political Psychology,

Conway III, L. G., Gornick, L. J., Houck, S. C., Anderson, C., Stockert, J., Sessoms, D., \& McCue, K. (2016). Are conservatives really more simple-minded than liberals? The domain specificity of complex thinking. Political Psychology, 37(6), 777-798.

Conway III, L. G., Houck, S. C., Gornick, L. J., \& Repke, M. A. (2018). Finding the Loch Ness monster: Left-wing authoritarianism in the United States. Political Psychology, 39(5), 10491067. 35(6), 841-851.

Costello, T. H., Bowes, S., Stevens, S. T., Waldman, I., Tasimi, A., \& Lilienfeld, S. O. (2020). Clarifying the structure and nature of left-wing authoritarianism.

Chmielewski, M., \& Kucker, S. C. (2020). An MTurk Crisis? Shifts in Data Quality and the Impact on Study Results. Social Psychological and Personality Science, 11(4), 464-473. https://doi.org/10.1177/1948550619875149

Dahl, R. A. (1971). Polyarchy: Participation and opposition. Yale University Press.

Dahl, R. A. (1998). On Democracy. New Haven and London.

Diamond, L. (2015a). In search of democracy. Routledge.

Diamond, L. (2015b). Facing up to the democratic recession. Journal of Democracy, 26(1), 141-155.

Diener, E. (1984). Subjective well-being. Psychological bulletin, 95(3), 542.

Diener, E., Suh, E. M., Lucas, R. E., \& Smith, H. L. (1999). Subjective well-being: Three decades of progress. Psychological bulletin, 125(2), 276.

Diener, E., Wirtz, D., Tov, W., Kim-Prieto, C., Choi, D. W., Oishi, S., \& Biswas-Diener, R. (2010). New well-being measures: Short scales to assess flourishing and positive and negative feelings. Social indicators research, 97(2), 143-156. 


\section{DEMOCRACY AND IDEOLOGY}

Dimlock, M., \& Gramlich, J. (2020, September 23). How America Changed During Donald Trump's Presidency. Retrieved from https://www.pewresearch.org/2021/01/29/how-america-changedduring-donald-trumps-presidency/

Ditto, P. H., Liu, B. S., Clark, C. J., Wojcik, S. P., Chen, E. E., Grady, R. H., ... \& Zinger, J. F. (2019). At least bias is bipartisan: A meta-analytic comparison of partisan bias in liberals and conservatives. Perspectives on Psychological Science, 14(2), 273-291.

Drutman, L. (2021, June 17). Why the Two-Party System is Effing Up U.S. Democracy. FiveThirtyEight. https://fivethirtyeight.com/features/why-the-two-party-system-is-wrecking-american-democracy/

Duggan, L. (2012). The twilight of equality?: Neoliberalism, cultural politics, and the attack on democracy. Beacon Press.

Egloff, B., Schmukle, S. C., Burns, L. R., Kohlmann, C. W., \& Hock, M. (2003). Facets of dynamic positive affect: differentiating joy, interest, and activation in the positive and negative affect schedule (PANAS). Journal of personality and social psychology, 85(3), 528.

Fandos, N., \& Michael. (2019, December 18). Trump Impeached for Abuse of Power and Obstruction of Congress. Retrieved from https://www.nytimes.com/2019/12/18/us/politics/trumpimpeached.html

Finkel, E. J., Bail, C. A., Cikara, M., Ditto, P. H., Iyengar, S., Klar, S., .. Druckman, J. N. (2020). Political sectarianism in America. Science, 370(6516), 533-536. https://doi.org/10.1126/science.abe1715

Feldman, S., \& Johnston, C. (2014). Understanding the determinants of political ideology: Implications of structural complexity. Political Psychology, 35(3), 337-358.

Fraga, B. L. (2018). The turnout gap: Race, ethnicity, and political inequality in a diversifying America. Cambridge University Press. 


\section{DEMOCRACY AND IDEOLOGY}

Freedom House (2019). Methodology: Freedom in the World 2018. Retrieved 27 October 2020.

Freedom House (2021). Freedom in the World 2021. Retrieved June 18, 2021, from https://freedomhouse.org/report/freedom-world/2021/democracy-under-siege

Galston, W. A., \& Galston, W. A. (1991). Liberal purposes: Goods, virtues, and diversity in the liberal state. Cambridge University Press.

Ganzach, Y., \& Schul, Y. (2020). Partisan Ideological Attitudes: Liberals Are Tolerant; the Intelligent Are Intolerant. Journal of Personality and Social Psychology. https://doi.org/10.1037/pspi0000324

Gauchat, G. (2012). Politicization of science in the public sphere: A study of public trust in the United States, 1974 to 2010. American sociological review, 77(2), 167-187.

Gerber, A. S., Huber, G. A., Doherty, D., Dowling, C. M., \& Ha, S. E. (2010). Personality and political attitudes: Relationships across issue domains and political contexts. American Political Science Review, 104(1), 111-133.

Goodman, J. K., Cryder, C. E., \& Cheema, A. (2013). Data Collection in a Flat World: The Strengths and Weaknesses of Mechanical Turk Samples. Journal of Behavioral Decision Making, 26(3), 213-224. https://doi.org/10.1002/bdm.1753

Frimer, J. A., Gaucher, D., \& Schaefer, N. K. (2014). Political conservatives' affinity for obedience to authority is loyal, not blind. Personality and Social Psychology Bulletin, 40(9), 1205-1214.

Frimer, J. A., Skitka, L. J., \& Motyl, M. (2017). Liberals and conservatives are similarly motivated to avoid exposure to one another's opinions. Journal of Experimental Social Psychology, 72, 1-12. 


\section{DEMOCRACY AND IDEOLOGY}

Ganzach, Y., \& Schul, Y. (2020). Partisan Ideological Attitudes: Liberals Are Tolerant; the Intelligent Are Intolerant. Journal of Personality and Social Psychology. https://doi.org/10.1037/pspi0000324

General Social Survey (2015). Same-Sex Marriage and Gay Rights: A Shift in Americans’ Attitudes. Retrieved August 8, 2018, from http://www.apnorc.org/projects/Pages/same-sex-marriage-andgay-rights-a-shift-in-americans-attitudes.aspx

Gomez, B. T., Hansford, T. G., \& Krause, G. A. (2007). The republicans should pray for rain: Weather, turnout, and voting in U.S. presidential elections. Journal of Politics, 69(3), 649-663.

Graham, J., Haidt, J., \& Nosek, B. A. (2009). Liberals and conservatives rely on different sets of moral foundations. Journal of personality and social psychology, 96(5), 1029.

Graham, J., Nosek, B. A., Haidt, J., Iyer, R., Koleva, S., \& Ditto, P. H. (2011). Mapping the moral domain. Journal of personality and social psychology, 101(2), 366.

Graham, M. H., \& Svolik, M. W. (2020). Democracy in America? Partisanship, Polarization, and the Robustness of Support for Democracy in the United States. American Political Science Review, 114(2), 392-409.

Haidt, J., \& Graham, J. (2007). When morality opposes justice: Conservatives have moral intuitions that liberals may not recognize. Social Justice Research, 20(1), 98-116.

Haidt, J., \& Graham, J. (2009). Planet of the Durkheimians, where community, authority, and sacredness are foundations of morality. Social and psychological bases of ideology and system justification, 371-401.

Haidt, J., Graham, J., \& Joseph, C. (2009). Above and below left-right: Ideological narratives and moral foundations. Psychological Inquiry, 20(2-3), 110-119.

https://doi.org/10.1080/10478400903028573 


\section{DEMOCRACY AND IDEOLOGY}

Haines, E. L., \& Jost, J. T. (2000). Placating the Powerless: Effects of Legitimate and Illegitimate Explanation on Affect, Memory, and Stereotyping. Social Justice Research, 13(3), 219-236.

Hansford, T. G., \& Gomez, B. T. (2010). Estimating the electoral effects of voter turnout. American Political Science Review, 104(2), 268-288.

Harmon-Jones, C., Bastian, B., \& Harmon-Jones, E. (2016). The discrete emotions questionnaire: A new tool for measuring state self-reported emotions. PloS one, 11(8), e0159915.

Helliwell, J. F. (1992). Empirical linkages between democracy and economic growth. National Bureau of Economic Research.

Hibbing, J. R., Smith, K. B., \& Alford, J. R. (2014). Differences in negativity bias underlie variations in political ideology. Behavioral and Brain Sciences, 37(3), 297-307. https://doi.org/10.1017/S0140525X13001192

Huntington, S. P. (1993). The third wave: Democratization in the late twentieth century (Vol. 4). University of Oklahoma press.

Inglehart, R. (1997). Modernization and postmodernization: Cultural, economic, and political change in 43 societies. Princeton University Press.

Iyengar, S., Sood, G., \& Lelkes, Y. (2012). Affect, not ideology: A social identity perspective on polarization. Public Opinion Quarterly, 76(3), 405-431.

Iyer, A., Schmader, T., \& Lickel, B. (2007). Why individuals protest the perceived transgressions of their country: The role of anger, shame, and guilt. Personality and Social Psychology Bulletin, 33(4), 572-587.

Iyer, R., Koleva, S., Graham, J., Ditto, P., \& Haidt, J. (2012). Understanding libertarian morality: The psychological dispositions of self-identified libertarians. PLOS ONE, 7(8). https://doi.org/10.1371/journal.pone.0042366 


\section{DEMOCRACY AND IDEOLOGY}

Jost, J. T. (2009). "Elective affinities": On the psychological bases of left-right differences. Psychological Inquiry, 20(2-3), 129-141.

Jost, J. T. (2017). Ideological Asymmetries and the Essence of Political Psychology. Political Psychology, 38(2), 167-208. https://doi.org/10.1111/pops.12407

Jost, J. T. (2019). A quarter century of system justification theory: Questions, answers, criticisms, and societal applications. British Journal of Social Psychology, 58(2), 263-314.

Jost, J. T., Banaji, M. R., \& Nosek, B. A. (2004). A decade of system justification theory: Accumulated evidence of conscious and unconscious bolstering of the status quo. Political psychology, 25(6), 881-919.

Jost, J. T., Becker, J., Osborne, D., \& Badaan, V. (2017). Missing in (Collective) Action: Ideology, System Justification, and the Motivational Antecedents of Two Types of Protest Behavior. Current Directions in Psychological Science, 26(2), 99-108. https://doi.org/10.1177/0963721417690633

Jost, J. T., Glaser, J., Kruglanski, A. W., \& Sulloway, F. J. (2003). Political conservatism as motivated social cognition. Psychological bulletin, 129(3), 339.

Jost, J. T., Halperin, E., \& Laurin, K. (2020). Editorial overview: Five observations about tradition and progress in the scientific study of political ideologies. Current Opinion in Behavioral Sciences, 34, iii.

Jost, J. T., Pelham, B. W., Sheldon, O., \& Ni Sullivan, B. (2003). Social inequality and the reduction of ideological dissonance on behalf of the system: evidence of enhanced system justification among the disadvantaged. European Journal of Social Psychology, 33(1), 13-36.

https://doi.org/10.1002/ejsp.127 


\section{DEMOCRACY AND IDEOLOGY}

Kay, A. C., \& Jost, J. T. (2003). Complementary justice: effects of” poor but happy” and” poor but honest" stereotype exemplars on system justification and implicit activation of the justice motive. Journal of personality and social psychology, 85(5), 823.

Kay, A. C., Gaucher, D., Peach, J. M., Laurin, K., Friesen, J., Zanna, M. P., \& Spencer, S. J. (2009). Inequality, discrimination, and the power of the status quo: Direct evidence for a motivation to see the way things are as the way they should be. Journal of personality and social psychology, 97(3), 421.

Kay, A. C., Jimenez, M. C., \& Jost, J. T. (2002). Sour grapes, sweet lemons, and the anticipatory rationalization of the status quo. Personality and Social Psychology Bulletin, 28(9), 1300-1312.

Kollmuss, A., \& Agyeman, J. (2002). Mind the gap: why do people act environmentally and what are the barriers to pro-environmental behavior?. Environmental education research, 8(3), 239-260.

Kroh, M. (2007). Measuring left-right political orientation: The choice of response format. Public Opinion Quarterly, 71(2), 204-220.

Kugler, M., Jost, J. T., \& Noorbaloochi, S. (2014). Another look at moral foundations theory: Do authoritarianism and social dominance orientation explain liberal-conservative differences in “moral” intuitions?. Social Justice Research, 27(4), 413-431.

Langer, M., Vasilopoulos, P., McAvay, H., \& Jost, J. T. (2020). System justification in France: liberté, égalité, fraternité. Current Opinion in Behavioral Sciences, 34, 185-191.

Lewin, K., Lippitt, R., \& White, R. K. (1939). Patterns of aggressive behavior in experimentally created “social climates". The Journal of social psychology, 10(2), 269-299.

Levitsky, S., \& Ziblatt, D. (2016, December 16). Is Donald Trump a Threat to Democracy? Retrieved November 25, 2020, from https://www.nytimes.com/2016/12/16/opinion/sunday/is-donaldtrump-a-threat-to-democracy.html 


\section{DEMOCRACY AND IDEOLOGY}

Lesschaeve, C. (2017). The predictive power of the left-right self-placement scale for the policy positions of voters and parties. West European Politics, 40(2), 357-377.

Litman, L., Robinson, J., \& Abberbock, T. (2017). TurkPrime.com: A versatile crowdsourcing data acquisition platform for the behavioral sciences. Behavior Research Methods, 49(2), 433-442. https://link.springer.com/article/10.3758/s13428-016-0727-z

Lührmann, A., Medzihorsky, J., \& Lindberg, S. I. (2021). Walking the Talk: How to Identify AntiPluralist Parties. SSRN Electronic Journal, (March). https://doi.org/10.2139/ssrn.3813132

Macpherson, C. B. (2016). 54. Democratic Theory, Essays in Retrieval (pp. 287-292). Columbia University Press.

Mallock, W. H. (2017). The limits of pure democracy. Routledge.

McAdams, D. P. (1995). What do we know when we know a person? Journal ofPersonality, 63(3), 365396.

McCoy, J., Simonovits, G., \& Littvay, L. (2020). Democratic hypocrisy: Polarized citizens support democracy-eroding behavior when their own party is in power.

Mettler, S., \& Lieberman, R. C. (2020). Four threats: The recurring crises of American democracy. New York, NY: St. Martin's Press.

Mischel, W. (2013). Personality and assessment. Psychology Press.

Moore-Berg, S. L., Ankori-Karlinsky, L. O., Hameiri, B., \& Bruneau, E. (2020). Exaggerated metaperceptions predict intergroup hostility between American political partisans. Proceedings of the National Academy of Sciences, 117(26), 14864-14872.

Morisi, D., Jost, J. T., \& Singh, V. (2019). An asymmetrical "president-in-power" effect. American Political Science Review, 113(2), 614-620. 


\section{DEMOCRACY AND IDEOLOGY}

Motta, M. (2018). The Dynamics and Political Implications of Anti-Intellectualism in the United States. American Politics Research, 46(3), 465-498. https://doi.org/10.1177/1532673X17719507

Napier, J. L., \& Jost, J. T. (2008). Why are conservatives happier than liberals?. Psychological Science, 19(6), 565-572.

Narveson, J. (2001). The libertarian idea. Broadview Press.

Nilsson, A., \& Jost, J. T. (2020). The authoritarian-conservatism nexus. Current Opinion in Behavioral Sciences, 34, 148-154.

Nolan, D. (1971). Classifying and analysing politico-economic systems. The Individualist, 1, 5-11.

Nozick, R. (1974). Anarchy, state, and utopia (Vol. 5038). New York: Basic Books.

Onraet, E., Van Assche, J., Roets, A., Haesevoets, T., \& Van Hiel, A. (2017). The happiness gap between conservatives and liberals depends on country-level threat: A worldwide multilevel study. Social Psychological and Personality Science, 8(1), 11-19.

Oppenheimer, D. M., Meyvis, T., \& Davidenko, N. (2009). Instructional manipulation checks: Detecting satisficing to increase statistical power. Journal of Experimental Social Psychology, $45,867-872$.

Osborne, D., Jost, J. T., Becker, J. C., Badaan, V., \& Sibley, C. G. (2019). Protesting to challenge or defend the system? A system justification perspective on collective action. European Journal of Social Psychology, 49(2), 244-269.

Oxley, D. R., Smith, K. B., Alford, J. R., Hibbing, M. V., Miller, J. L., Scalora, M., ... Hibbing, J. R. (2008). Political attitudes vary with physiological traits. Science, 321(5896), 1667-1670. https://doi.org/10.1126/science.1157627

Palan, S., \& Schitter, C. (2018). Prolific.ac-A subject pool for online experiments. Journal of Behavioral and Experimental Finance, 17, 22-27. https://doi.org/10.1016/j.jbef.2017.12.004 


\section{DEMOCRACY AND IDEOLOGY}

Paolacci, G., \& Chandler, J. (2014). Inside the Turk: Understanding Mechanical Turk as a Participant Pool. Current Directions in Psychological Science, 23(3), 184-188. https://doi.org/10.1177/0963721414531598

Pavot, W., \& Diener, E. (1993). The affective and cognitive context of self-reported measures of subjective well-being. Social Indicators Research, 28(1), 1-20.

Peer, E., Brandimarte, L., Samat, S., \& Acquisti, A. (2017). Beyond the Turk: Alternative platforms for crowdsourcing behavioral research. Journal of Experimental Social Psychology, 70, 153-163. https://doi.org/10.1016/j.jesp.2017.01.006

Pew Research Center (2017a). Globally, Broad Support for Representative and Direct Democracy. Retrieved from https://www.pewresearch.org/global/2017/10/16/globally-broad-support-forrepresentative-and-direct-democracy/

Pew Research Center (2018a). How Americans see their country and their democracy. Retrieved from http://www.pewresearch.org/fact-tank/2018/07/04/how-americans-see-their-country-and-theirdemocracy/

Pew Research Center. (2018b). Conservative Republicans are least supportive of making it easy for everyone to vote. Retrieved from https://www.pewresearch.org/facttank/2018/10/31/conservative-republicans-are-least-supportive-of-making-it-easy-for-everyoneto-vote/

Pew Research Center. (2019a). Democratic Rights Popular Globally but Commitment to Them Not Always Strong. Retrieved from https://www.pewresearch.org/global/2020/02/27/democraticrights-popular-globally-but-commitment-to-them-not-always-strong/

Pew Research Center. (2019b). Attitudes on Same-Sex Marriage. Retrieved from http://www.pewforum.org/fact-sheet/changing-attitudes-on-gay-marriage/ 


\section{DEMOCRACY AND IDEOLOGY}

Plattner, M. F. (2015). Is democracy in decline?. Journal of Democracy, 26(1), 5-10.

Pliskin, R., Ruhrman, A., \& Halperin, E. (2020). Proposing a multi-dimensional, context-sensitive approach to the study of ideological (a)symmetry in emotion. Current Opinion in Behavioral Sciences, 34, 75-80. https://doi.org/10.1016/j.cobeha.2020.01.005

Proch, J., Elad-Strenger, J., \& Kessler, T. (2019). Liberalism and conservatism, for a change! Rethinking the association between political orientation and relation to societal change. Political Psychology, 40(4), 877-903.

Przeworski, A., Alvarez, R. M., Alvarez, M. E., Cheibub, J. A., Limongi, F., \& Neto, F. P. L. (2000). Democracy and development: Political institutions and well-being in the world, 1950-1990 (No. 3). Cambridge University Press.

Reis, H. T. (2008). Reinvigorating the concept of situation in social psychology. Personality and Social Psychology Review, 12(4), 311-329. https://doi.org/10.1177/1088868308321721

Ross, L., \& Nisbett, R.E. (1991). The person and the situation: Perspectives ofsocial psychology. New York: McGraw-Hill

Schatz, Robert T., Ervin Staub, and Howard Lavine. (1999). On the Varieties of National Attachment: Blind versus Constructive Patriotism. Political Psychology 20(1):151-74.

Schumpeter, J. A. (1942). Capitalisim, Socialism and Democracy. Edinburgh University Press.

Shook, N. J., \& Fazio, R. H. (2009). Political ideology, exploration of novel stimuli, and attitude formation. Journal of Experimental Social Psychology, 45(4), 995-998. https://doi.org/10.1016/j.jesp.2009.04.003

Sibley, C. G., \& Duckitt, J. (2008). Personality and prejudice: A meta-analysis and theoretical review. Personality and Social Psychology Review, 12(3), 248-279. 


\section{DEMOCRACY AND IDEOLOGY}

Sidanius, J., Pratto, F., \& Bobo, L. (1996). Racism, conservatism, affirmative action, and intellectual sophistication: A matter of principled conservatism or group dominance?. Journal of personality and social psychology, 70(3), 476.

Singer, P. (1973). Democracy and disobedience. Clarendon Press.

Skitka, L. J. (2002). Do the means always justify the ends, or do the ends sometimes justify the means? A value protection model of justice reasoning. Personality and Social Psychology Bulletin, 28(5), 588-597.

Skitka, L. J., \& Mullen, E. (2002). Understanding judgments of fairness in a real-world political context: A test of the value protection model of justice reasoning. Personality and Social Psychology Bulletin, 28(10), 1419-1429.

Skitka, L. J. (2010). The psychology of moral conviction. Social and Personality Psychology Compass, $4(4), 267-281$.

Skitka, L. J., \& Bauman, C. W. (2008). Moral conviction and political engagement. Political Psychology, 29(1), 29-54. https://doi.org/10.1111/j.1467-9221.2007.00611.x

Steiger, R. L., Reyna, C., Wetherell, G., \& Iverson, G. (2019). Contempt of congress: Do liberals and conservatives harbor equivalent negative emotional biases towards ideologically congruent vs. incongruent politicians at the level of individual emotions? Journal of Social and Political Psychology, 7(1), 100-123. https://doi.org/10.5964/jspp.v7i1.822

Stern, C., \& Crawford, J. T. (2021). Ideological conflict and prejudice: An adversarial collaboration examining correlates and ideological (a) symmetries. Social Psychological and Personality Science, 12(1), 42-53.

Stutzer, A., \& Frey, B. S. (2003). Institutions matter for procedural utility: An econometric study of the impact of political participation possibilities. Chapters. 


\section{DEMOCRACY AND IDEOLOGY}

Sullivan, J. L., \& Transue, J. E. (1999). The psychological underpinnings of democracy: A selective review of research on political tolerance, interpersonal trust, and social capital. Annual review of psychology, 50(1), 625-650.

The Economist Intelligence Unit. (2016). Democracy Index 2016. Retrieved August 8, 2018, from https://www.eiu.com/public/topical_report.aspx?campaignid=DemocracyIndex2016

The Economist Intelligence Unit. (2021). Democracy Index 2020: In sickness and in health? Retrieved February 7, 2021, from https://www.eiu.com/n/campaigns/democracy-index2020/\#mktoForm_anchor

The Heritage Foundation. (2014). 2014 Index of Economic Freedom. Retrieved August 9, 2018, from https://www.heritage.org/index/explore

Toner, K., Leary, M. R., Asher, M. W., \& Jongman-Sereno, K. P. (2013). Feeling superior is a bipartisan issue: Extremity (not direction) of political views predicts perceived belief superiority. Psychological Science, 24(12), 2454-2462.

Transparency International. (2015). Corruption Perceptions Index 2015. Retrieved August 8, 2018, from https://www.transparency.org/cpi2015

United Nations Development Program. (2014). Human Development Index 2014. Retrieved August 8, 2018, from http://hdr.undp.org/en/data

Uhlmann, E. L., Pizarro, D. A., Tannenbaum, D., \& Ditto, P. H. (2009). The motivated use of moral principles. Judgment and Decision making, 4(6), 479-491.

Waldron, T. (2020, September 16). 'We Weren't Alarmist Enough': Experts Warn Trump And GOP Could Destroy Democracy. Retrieved October 07, 2020, from https://www.huffingtonpost.ca/entry/trump-republicans-democracy-atrisk_n_5f5fb18fc5b6e27db1314744?ri18n=true 


\section{DEMOCRACY AND IDEOLOGY}

Watson, D., Clark, L. A., \& Tellegen, A. (1988). Development and validation of brief measures of positive and negative affect: the PANAS scales. Journal of personality and social psychology, 54(6), 1063.

Webber, D., Kruglanski, A., Molinario, E., \& Jasko, K. (2020, August 1). Ideologies that justify political violence. Current Opinion in Behavioral Sciences, Vol. 34, pp. 107-111. F.

Welzel, C. (2013). Freedom rising. Cambridge University Press.

Wilson, A. R., \& Burack, C. (2012). "Where liberty reigns and God is supreme": the Christian right and the Tea Party movement. New Political Science, 34(2), 172-190.

Wagenmakers, E. J. (2007). A practical solution to the pervasive problems of p values. Psychonomic Bulletin and Review, 14(5), 779-804. https://doi.org/10.3758/BF03194105

Washington Post. (2021). Washington Post-ABC News poll, January 10-13 [Data set]. Retrieved from: https://context-cdn.washingtonpost.com/notes/prod/default/documents/b2030ff6-7d13-4e1283b1-42ef7ace3da5/note/b5008a8e-3565-4eae-83d9-de48d22eeaf5.\#page =1

Wetherell, G. A., Brandt, M. J., \& Reyna, C. (2013). Discrimination across the ideological divide: The role of value violations and abstract values in discrimination by liberals and conservatives. Social Psychological and Personality Science, 4(6), 658-667.

World Bank Group (2014). The World Bank Annual Report 2014. Retrieved from https://doi.org/10.1596/978-1-4648-0245-4

Zakaria, F. (1997). The rise of illiberal democracy. Foreign Affairs, 76(6), 22-39. https://doi.org/10.2307/20048274

Zuell, C., \& Scholz, E. (2019). Construct Equivalence of Left-Right Scale Placement in a CrossNational Perspective. International Journal of Sociology, 49(1), 77-95 
DEMOCRACY AND IDEOLOGY 